\title{
El Intersticio como nuevo soporte del Diseño Urbano de la sociedad contemporánea
} Interstice as the new foundation of contemporary society's urban design

Gonzalo Horacio Arze Arce

\section{Filiación}

Universidad de Chile

E mail: garze@uchilefau.cl

\section{Resumen}

Es evidente que las presiones del mundo contemporáneo (propias de la globalización, tecnologías de la información, capitalismo, individualismo, entre otras), han transformado considerablemente la manera en cómo se está representando la condición del espacio urbano. Este proceso se ha encargado de marcar fuertemente el límite entre una condición y otra, siendo la esfera privada que prevalece y fagocita constantemente a la esfera pública.

El presente artículo tiene como objetivo por una parte, establecer algunos criterios para reflexionar el concepto de intersticio y posicionarlo en un encuadre donde la sociedad contemporánea opera y se desenvuelve. Por otra parte, a través tres casos distintos entre sí y con particularidades propias, se reflexiona y evidencia que a partir de un espacio constituido de forma tradicional, es posible esbozar aproximaciones que superan las condiciones físicas y reconfigurarlo en función del intersticio.

Las condiciones solamente orientadas a la resolución física formal y funcional son insuficientes para poder entender la contemporaneidad de la sociedad. Por ello, se presenta como criterios imperantes, la autogestión participativa, clave a la hora de orientar nuevas formas de ocupar y entender el espacio, considerando el despliegue perceptual del usuario permitiendo un entorno más flexible, adaptable y multifuncional. Es aquí que la constante del intersticio aparece como una posibilidad para aproximarse a la comprensión de esta dualidad que parece no resuelta.

\section{Palabras Claves}

Diseño Urbano; Espacio público, espacio privado; Intersticio; Sociedad Contemporánea

\begin{abstract}
Clearly the pressures of the modern world (characteristic of globalization, information technology, capitalism, individualism, etc.), have significantly transformed the way how are representing the condition of urban space. This process has been commissioned to strongly mark the boundary between a condition and another, with the private sphere and constantly engulfs prevailing public sphere.

This article aims on the one hand, to establish some criteria to reflect the concept of interstice and position in a frame where contemporary society operates and develops. Moreover, through three different cases together and specificities, and reflects evidence from a space constituted the traditional way, it is possible to outline approaches that go beyond the physical conditions and reconfigure depending on the interstice.

The conditions only oriented formal and functional physical resolution is insufficient to understand contemporary society. Therefore, it comes as prevailing criteria, participatory self, key in guiding new ways to occupy and understanding space, considering the perceptual user deployment allowing more flexible, adaptable and multifunctional environment. It is here that the constant interstice appears as a possibility to approach the understanding of this duality that seems unresolved.
\end{abstract}

\section{Keywords}

Urban Design; Public space, private space; interstice; Contemporary Society 


\section{Sumario}

Introducción.

1 El Concepto de Intersticio.

2 El Intersticio y su condición socio-espacial.

3 Paradigmas de la Sociedad Actual.

4 Modelamiento sobre los Casos de estudio.

4.1 Caso 1: Puerta del Sol.

4.2 Caso 2: Plaza de Torico.

4.3 Caso 3: La Plaza de la Encarnación.

5 Categorías de Análisis (Modos de Intervención)

6 Reconfiguración del Espacio Urbano.

Conclusiones y consideraciones finales.

Bibliografía.

\section{Introducción}

La arquitectura y el urbanismo han buscado durante mucho tiempo la forma de abordar las transformaciones del espacio físico y la manera de operar en éste. Ambas disciplinas son protagonistas del soporte físico de la ciudad actual, pero es el diseño urbano la disciplina que logra articularlas y relacionarlas, asumiendo el espacio público urbano como objeto de estudio. ${ }^{1}$

Durante el siglo $X X$ se han considerado criterios epistemológicos de corrientes tradicionales (funcionalista, racionalista y empirista), bajo fundamentos conducentes a la razón, experiencia y acción respectivamente. Éstos han influenciado fuertemente en la concepción del espacio urbano construido de las ciudades del mundo contemporáneo. ${ }^{2}$

Si bien estas corrientes han sido determinantes a la hora de construir la ciudad, hoy en día, su complejidad ha puesto en cuestionamiento la manera de abordar las nuevas dinámicas de una sociedad actual ${ }^{3}$, cada vez más flexible y que se encuentra en constante cambio.

Así, la sociedad actual se desenvuelve sobre nuevos paradigmas, que influyen en la interpretación del espacio urbano de modos materiales o inmateriales, las redes comunicacionales permiten diferentes modos de interacción, intensificando fenómenos y relaciones sociales que antes se consagraban en el espacio urbano tradicional, observándose en la actualidad de manera más espontanea e instantánea, cambiando las dinámicas tradicionales antes advertidas.

El uso de las tecnologías de la información ${ }^{4}$ han transformado la manera de actuar de la sociedad, y por tanto el significado social del espacio urbano ${ }^{5}$. También ha adquirido importancia la influencia del auge del capitalismo en la configuración de la ciudad, que se ha apropiado de los espacios que quedaban vacantes ${ }^{6}$, y que ha modificado la manera de concebir la acción social antes característica del espacio urbano, bajo nuevas condiciones selectivas, donde la seguridad

${ }^{1}$ (Arze, et al.: 2013)

${ }^{2}$ (Ordeig: 2004)

3 (Gehl: 2003)

${ }^{4}$ (Castells: 2002)

5 (Bencomo: 2011)

${ }^{6}$ (Lefebvre: 1974) 
e individualismo se asoman como características protagonistas de un modo de plantear el espacio destinado a una sociedad de creciente consumo. De esta manera, también el espacio urbano se ve afectado bajo las presiones formales y funcionales ejercidas por la esfera privada sobre la esfera pública.

Tanto las tecnologías de la información como el auge del capitalismo (y probablemente otras variables de igual importancia que no están explicadas en este artículo) se definen como nuevos paradigmas de una realidad compleja que influye en la sociedad actual en su modo de habitar la ciudad. La sociedad informacional ${ }^{7}$, ha dado paso a nuevas maneras de interactuar o relacionarse a través de redes sociales u otras plataformas virtuales. Castells en este sentido nos habla de un nuevo tipo de espacio (virtual) relacionado a los flujos.

En este sentido, las personas tienden cada vez a establecer otro tipo de relación, mucho más concentrada en el individualismo y la autonomía, lo cual impulsa a realizar actividades en recintos cerrados o privados, alejándose de conceptos que eran vitales para relaciones sociales "tradicionales" que tenían su soporte físico en el espacio público ${ }^{8}$.

La necesidad de entender esta aproximación es importante en cuanto se requiere cambiar la manera de concebir el espacio urbano tradicional, considerando las nuevas condiciones que ofrece la sociedad contemporánea, permitiendo la exploración del concepto "intersticio" a través de su constante intermedia articuladora y resolutiva del conflicto existente entre la esfera pública y la privada.

Entonces, paralelamente a lo anterior, entendemos que los nuevos paradigmas no han sido visualizados en la mayoría de los casos desde nuestra disciplina, ocasionando limitantes a la hora de postular alternativas de solución en el entorno socioespacial. Más aún, otras disciplinas como por ejemplo la sociología, antropología, psicología, filosofía, entre otras, han tenido el rigor de observar con mayor atención estos cambios que dan cuenta de esta condición y esbozar diferentes categorías que transgreden en muchos casos el ámbito físico.

Ahora bien, independiente a que cada espacio que se considere como caso de estudio y tenga propiedades y características particulares, en rigor, cualquier espacio donde la condición dual público-privado esté presente, tiene gran potencial de identificar al intersticio como constante. Este potencial está dado principalmente por las condiciones que el usuario va desplegando en el lugar, la forma de ocupación, y principalmente la forma en que percibe contemporáneamente un espacio.

De esta manera, el intersticio posiblemente soporta una realidad que se solventa en una configuración que se transgrede, en muchos casos, el escenario es el mismo pero su condición cambia, se vinculan significados que la sociedad interpreta acorde a la realidad ${ }^{9}$. Es cierto que es un hecho aislado, pero lo que prevalece es la intención de la sociedad de modificar las leyes del espacio en torno a su configuración y función.

Claramente los criterios con los cuales se ha trabajado y en muchos casos se está trabajando el diseño urbano hoy día están siendo cuestionados al no responder claramente a las necesidades que el mundo contemporáneo exige. Entonces, bajo la dinámica actual de la sociedad, la comprensión de la ciudad desde el diseño urbano requiere nuevas aproximaciones de análisis y propone una serie de cuestionamientos: ¿Cuál es la posible relación entre lo público y lo privado? ¿Cuáles son las modalidades del espacio público hoy?; ¿Cómo influyen la reinterpretación del "intersticio" en la configuración o definición de la estructura urbana contemporánea? ¿De qué

\footnotetext{
${ }^{7}$ (Castells: 2002)

8 (Valencia: 2005)

${ }^{9}$ (Bacon: 1974)
} 
manera la sociedad se va amoldando y va reconfigurando su condición en el espacio público? A lo largo del presente artículo se discutirán estos cuestionamientos.

El presente escrito se organiza en tres partes. En la primera parte se trabaja sobre algunas aproximaciones conceptuales que establecen la conceptualización del "intersticio" como objeto de estudio. En una segunda parte, se considera tres casos de análisis, los cuales fueron elegidos cumpliendo la condición tradicional de configuración físico espacial, pero que con una aproximación diferente en la reconceptualización de estos espacios, se convierten en entornos contemporáneos. En una última parte, se discuten algunas reflexiones sobre la instauración de este nuevo concepto, las posibles categorías de análisis en los modos de intervención, sus implicancias en los casos de estudio y su posible aporte dentro de la disciplina del diseño urbano.

\section{El Concepto de Intersticio}

"Tradicionalmente, el diseño urbano se ha encargado de diseñar la calle y la plaza, asumiendo que ese espacio público se lo define bajo ciertas categorías que responden a variables políticas, administrativas, físicas, funcionales, entre otras, de carácter muy restrictivo, muy limitante en circunstancias en que la propia sociedad ha rebasado o está rompiendo esas barreras. Esas categorías que limitaban el ámbito público y el privado se están diluyendo desde el punto de vista de la sociedad, de los individuos, del habitar observando una transgresión a esas categorías que separaban ambas esferas, como también desde el punto de vista espacial, físico y funcional"10.

El concepto de intersticio como soporte del diseño urbano, no prioriza la condición que limita el ámbito público y el privado, sino más bien, incorpora todo aquello que queda "entre" ambos e incluso transgrede barreras del ámbito privado. "Es una condición que en muchos casos sobrepasa las dimensiones físicas, configurando nuevas instancias en las cuales el límite divisorio podría llegar a ser infiltrable o indefinido"11.

Estas aproximaciones a la definición de intersticio, pone en relevancia aquel vínculo homeostático que se encuentra entre todo aquello que se considere público y privado, resuelto en una condición.

El concepto mismo tradicionalmente entendido conlleva a una constante que se caracteriza por aquello que está "entre" dos partes. Ya sea un límite, un encuentro, una superficie donde convergen dos medios diferentes o funciones al menos distintas ${ }^{12}$. Funcionan como un límite bien definido, en el cual cada una de las condiciones cumple un rol específico provocando una dualidad, su configuración por tanto es ambigua, por ejemplo, en el ámbito de la medicina, el líquido intersticial de la sangre (plasma) es el fluido para permitir el desplazamiento de los glóbulos rojos (células) (Fig. 1). Asimismo, dentro de nuestra disciplina, hemos entendido el espacio intersticial "tradicional" como aquel restante que van dejando las operaciones autistas, espacios que necesitan para alcanzar su fin pero quedan atrapados en el medio sin construirse.

\footnotetext{
${ }^{10}$ (Arze, et. Al: 2013)

${ }^{11}$ (Arze, et. al.: 2013)

12 (Arze, et. al.: 2013)
} 


\section{REVISTA DE \\ URBANISMO}

ISSN 0717-5051

http://revistaurbanismo.uchile.cl
Revista de Urbanismo N³1 - Julio - Diciembre de 2014 Departamento de Urbanismo - FAU - Universidad de Chile

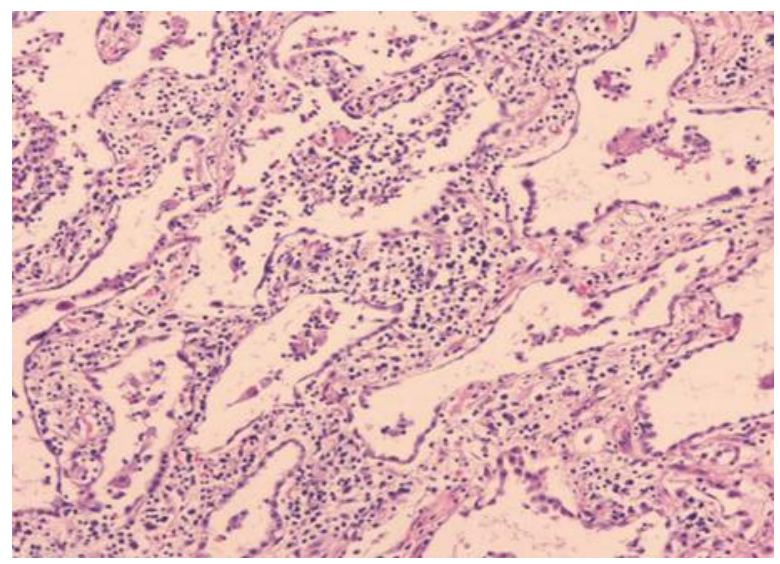

Fig. 1

Fuente: http://www.kidneypathology.com/Enf_tubulointerst.html

Es aquí donde es necesario replantear esta concepción tradicional con la cual el diseño urbano ha venido trabajando. Reconfigurar significa la exploración y resolución de la condición dual existente entre la esfera pública y privada cada vez más difusa y claramente poco definida en la contemporaneidad.

Las corrientes tradicionales se han encargado de configurar la ciudad de modo que la esfera pública y privada quede diferenciada y dividida en la ciudad sin mayor relación o dialogo entre ellas ${ }^{13}$, configuraciones o funciones que pretenden determinar un modo exacto de habitar que predispone además de un tiempo y condiciones insolventes a la realidad actual. Es en este aspecto que no se considera la dimensión social y su condición dinámica que sobrepasa esta restricción o barrera impuesta.

Desde la perspectiva del urbanismo y la arquitectura esto ha tenido una repercusión en el modo en que la sociedad se relaciona con su entorno, se evidencian espacios urbanos que no son utilizados, en otros casos su configuración solo determina erróneas funciones ${ }^{14}$, que conllevan a lo mismo, no ser habitados, o se utilizan pero de maneras distintas a las concebidas, aquí el espacio se torna distinto, cambia de acuerdo a las necesidades sociales. De esta manera se entiende una relación equivoca entre lo que se construye y lo que se hace.

..."también se evidencia la tesis -desde el punto de vista social- de concebir el espacio público, como lugares que adquieren significados como consecuencia de su utilización, de la circulación y los patrones de movilidad de los individuos y los grupos sociales, no obstante, se reconoce al mismo tiempo, la consecuencia de la interacción de las nuevas tecnologías de la información y los procesos de cambios sociales, sobre la forma urbana y el espacio público"15.

Por otra parte, el espacio de índole privado tiende a realizar actividades en ambientes cerrados, la acción social se genera bajo condiciones de control y selectividad de los individuos, afectando al espacio público en relación a funciones atribuibles a otras épocas, perdiendo terreno en lo

13 (Joseph: 2002)

14 (Arze, et al.: 2013)

15 (Bencomo: 2011) 
espacial y en lo significativo social, consagrando al espacio de propiedad privada como principal ente conformador de la ciudad ${ }^{16}$.

Lo anterior evidencia la necesidad de reconfigurar los límites del espacio público de acuerdo a los nuevos parámetros en que la sociedad se desenvuelve. Aquí es donde el concepto de intersticio puede lograr superar la manera tradicional de hacer y pensar la ciudad a través de su condición principal, relacionar y articular el ámbito público y privado posibilitando resolver una dualidad que ya no es aceptada por el colectivo (La entiende pero no la comparte).

El intersticio entonces, se presenta como el "soporte" contemporáneo para reflexionar y aplicar la disciplina del diseño urbano, permitiendo un dialogo homeostático entre las partes que constituyen un medio. Por tanto, mantiene una condición estable de equilibrio dinámico y flexible que regula el entorno (esfera pública - esfera privada), similar a lo que sucede con el comportamiento de una ameba, en la cual su constante es dinámica y cambiante ${ }^{17}$.

\section{El Intersticio y su condición socio-espacial}

Se ha insistido en que las condiciones del espacio urbano tradicionales son "disfuncionales" a la realidad en la que el usuario se desenvuelve, donde no se aprecia un "significado", una forma de interpretar los entornos físicos acorde a los tiempos contemporáneos. El diseño urbano tradicional por tanto, no es suficiente para cumplir la condición de intersticio, sus alcances solamente visualizan los elementos físicos del medio (medio ambiente construido) ${ }^{18}$ por lo que la reinterpretación del espacio físico debe concebir esta nueva realidad contemporánea a través de los nuevos significados que la sociedad otorgue.

Asi, la arquitectura es considerada un fenómeno cultural, por tanto puede ser la semiótica una manera de estudiar su interpretación, pero existe también un paradigma a la hora de hablar si la arquitectura realmente comunica, o más bien solo funciona, es necesario entender como "algo" que puede comunicar. En este sentido entendemos a rasgos generales que "algo" que comunica debe generar un estímulo, un comportamiento, una reacción que finalmente es interpretada por la persona. Desde este punto de vista, la arquitectura funciona y se desenvuelve, y es esta función la que se puede interpretar, así, logra comunicar, es decir, genera un estímulo que se traduce en su uso ${ }^{19}$.

Volviendo al intersticio y a su condición dual, encontramos ciertos prospectos que no se vinculan a la lógica comunicacional de la arquitectura determinada en un uso funcional interpretativo. Lo que sucede entonces es que la "función tradicional" del espacio configurado, se aleja del "estimulo contemporáneo". De esta manera que se logra interpretar la función, aquella que supone lo establecido, pero su estimulo no predispone un uso lógico relacionado a dicha función. Aparecen nuevas formas de apropiación y uso del espacio físico.

Humberto Eco, hace referencia a que en la arquitectura no solo a través de una determinada función se logra hacer uso de ella, sino que también es necesario identificar significados vinculantes, que predispongan al usuario para hacer uso funcional ${ }^{20}$. Estos significados deben estar relacionados con aquellas experiencias vividas o transmitidas que el usuario va experimentando con el paso del tiempo sobre un lugar determinado ${ }^{21}$.

\footnotetext{
16 (Bencomo: 2011)

17 (Arze, et al.: 2013)

18 (Trieb: 1983); (Carmona: 2003)

19 (Eco: 1974)

${ }^{20}$ (Eco: 1974); (Bacon: 1974)

21 (Trieb: 1985)
} 
Por tanto, estos espacios pierden significados vinculados a la sociedad actual, lo que hace que se tornan ambiguos emergiendo la condición dual (público - privado) del intersticio por sobre su condición natural homeostática. El ejercicio del diseño urbano en la reinterpretación de estos espacios apunta a significados asociados a la realidad social, dinámica y flexible. Los significados a su vez, están asociados a nuevas configuraciones que relacionan lo público con lo privado, de modo de establecer situaciones "entre" los dos ámbitos, y que su interpretación permita esta lectura por parte del usuario y asomar así la condición natural del intersticio.

\section{Paradigmas de la Sociedad Actual}

Las nuevas dinámicas de la sociedad, han evolucionado de manera ininterrumpida durante las últimas décadas, en consecuencia la flexibilidad y movilidad presentes son puntos fundamentales a la hora de entender una realidad que pareciera ir desarrollándose a velocidades mayores a las respuestas o soluciones encontradas en la ciudad. Así, comprender la realidad actual en la que se desenvuelve la sociedad nos permite observar de qué manera se comprende la ciudad, sus espacios, construcciones, la arquitectura y el urbanismo que son los pilares tangibles de las urbes del mundo. Es importante por tanto, entender cuáles son las nuevas variables que influyen en esta sociedad, de manera de probar la inconsecuencia del diseño urbano más tradicionalista, en relación a la realidad contemporánea y su modo de interpretación.

Uno de los factores que han dado pie a nuevos procesos sociales que generan sin duda una mayor flexibilidad en la sociedad son las redes informacionales, su influencia por tanto repercute en la manera de desenvolverse en el campo tangible de la ciudad. Las nuevas formas de interacción y relación que se efectúan a través de redes o plataformas cibernéticas ${ }^{22}$, genera un impacto en los espacios urbanos desde la perspectiva social y su manera de enfrentarlos en la realidad. Los postulados de Castells acerca de esta nueva era informacional y su impacto en la sociedad y el espacio se traduce en lo que él define como espacio de los flujos, producto de las tecnologías de red, y donde se realizan las funciones dominantes de la sociedad actual, con lo que el significado de los espacios tangibles queda atrapado ahora en esta nueva dinámica.

Si la sociedad se vuelve más flexible, movible, gracias a la aportación de las redes comunicacionales, y su espacio virtual, el tiempo también lo hace, entregando un valor agregado a la utilización de la tecnología ${ }^{23}$. Los espacios urbanos públicos por tanto, se vuelven disociados bajo este nivel de entendimiento, la globalización permitida por la interconectividad que brinda el espacio de los flujos, queda alejada de patrones culturales, o históricos característicos de los lugares físicos.

"Mi hipótesis es que la llegada del espacio de los flujos está opacando la relación significativa entre la arquitectura y la sociedad. Puesto que la manifestación espacial de los intereses dominantes se efectúa por todo el mundo y en todas las culturas, el desarraigo de la experiencia, la historia y la cultura específica como trasfondo del significado está llevando a la generalización de una arquitectura ahistórica y acultural"24.

En la actualidad el espacio público y urbano se entiende de una manera distinta a las concepciones del siglo XX. El comportamiento que la sociedad contemporánea ejerce sobre esta

\footnotetext{
22 Norbert Ver Wiener (1948) explica que la cibernética es esencialmente una ciencia de la información de control y de los sistemas de conocimiento y control. El significado etimológico de la palabra cibernética significa « el acto de maniobrar un buque, para gobernar (Kubenêsis griego). Asimismo, era consciente del impacto que la aplicación de la cibernética tendría en la sociedad. Por una parte, las máquinas inteligentes podrían realizar el trabajo humano. Por otra parte, la cibernética también podrían ser una fuente de inspiración positiva y fructífera para la invención del "capitalismo con rostro humano", el hombre conciliación, la economía y el medio ambiente.
}

23 (Bauman: 2003)

${ }^{24}$ (Castells: 2002) 
condición física, se debe a patrones de movimiento, las relaciones humanas se vuelven más espontaneas y se dan de manera inesperada, su interpretación es más flexible ${ }^{25}$, el hecho entonces de concebirlos definidamente como público o privado pierde relevancia a la aproximación de cómo se utilizan o se experimentan las relaciones humanas ${ }^{26}$, pero dentro de este patrón flexible se entiende la influencia creada por las redes comunicacionales y el espacio de los flujos. El espacio urbano público es el espacio de las experiencias sociales, aquí se dan las manifestaciones, relaciones, pero que con la ayuda de tecnologías comunicacionales se intensifica, volviéndose un espacio impredecible en el cual, el usuario accede a ellos, los recorre y los atraviesa. (Transgrede límites tangibles), Bencomo menciona a Castells para referirse al impacto del espacio de los flujos sobre el espacio de la ciudad.

Paralelamente a lo anterior, otro factor que ha incidido para que la sociedad se incline, como otra caracterización universal, en el ámbito privado, es el capitalismo, condición que se expresa a través de los espacios de consumo, diseñados exclusivamente para cumplir esta función. Así, la esfera privada ha incidido profundamente en los espacios públicos, volviéndose uno de los ejes principales de la realidad contemporánea.

Marcos Valencia alude a la Postmodernidad como eje central de nuevas espacialidades que se alejan de lugares antropológicos (refiriéndose a Marc Auge y su conceptualización), carentes de relaciones históricas e identitarias. Así, el capitalismo expansivo presente en la ciudad, ha llevado a la intervención arquitectónica a satisfacer necesidades de una sociedad de consumo (centros comerciales, malls, strip centers, multitiendas, etc.) privatizando la ciudad y generando la depreciación física y simbólica del espacio público ${ }^{27}$.

El espacio público se ve desfavorecido bajo esta aproximación, la tendencia de la sociedad de ejercer actividades sociales en espacios cerrados asiste la ideología capitalista, y el consumo de la sociedad como precursor de ella. Para Henry Lefebvre (1974), la necesidad y demanda capitalista ha tenido un impacto tan importante en la ciudad, que ya no solo se producen objetos en el espacio, sino que esta fuerza también produce el espacio mismo. En esta misma línea, Harvey observa el espacio urbano como una oportunidad de inversión de capital (el espacio de hoy en día se ve como un producto de consumo, una mercancía) ${ }^{28}$.

Consecuente a lo anterior, el espacio urbano público se ve fagocitado permanentemente por la tendencia capitalista, entonces también sus condiciones quedan evidenciadas en relación a la selectividad impuesta a ciertos grupos sociales, la concepción de estos espacios de carácter privado no permite la relaciones de carácter social, por tanto, sus límites tangibles están muy bien establecidos y definidos, incapaces de ser trasgredidos por la sociedad, los acontecimientos en su entorno tienen poca relevancia, manifestando una creciente polaridad entre lo público y privado.

Marc Auge (1993) sigue una línea en relación a la nueva manera de entender el comportamiento del usuario dentro de lugares o tipologías adoptadas y masificadas por el capitalismo, los supermercados, los centros comerciales, entre otros. Para este autor son reflejo de la sobre modernidad 29 , donde las relaciones sociales carecen de sentido y se expresan en los "no lugares", prevalece la interacción con imágenes o textos u otras consideraciones ${ }^{30}$. Lugares que carecen

\footnotetext{
25 (Bauman: 2003, 2006); (Delgado: 1999); (Sennett: 1978)

26 (Gehl: 2003)

27 (Valencia: 2005)

28 (Harvey: 1989)

29 La sobremodernidad (que procede simultáneamente de las tres figuras del exceso que son la superabundancia de acontecimientos, la superabundancia espacial y la individualización de las referencias) encuentra naturalmente su expresión completa en los no lugares (definido por Marc Auge).

30 (Auge: 1993)
} 
de identidad, más bien generan un sentido de soledad del individuo, no hay relación posible o sentido histórico no es un lugar antropológico (de manifestación o acción social) ${ }^{31}$.

\section{Modelamiento sobre los Casos de estudio}

Para aproximarnos con mayor precisión al entendido y puesta en escena de la condición "intersticio", se ha elegido tres casos de análisis considerando ciertos criterios: El primero, debía constituirse el espacio urbano manteniendo una configuración formal y funcional tradicional, respetando aquellos principios iniciales con los cuales se han diseñado y conformado el espacio físico. Por lo general, son espacios constituidos en la ciudad, centrales, de fácil accesibilidad y con carácter representativo. Segundo, espacios que tuvieran la posibilidad de adoptar ciertas modificaciones del mundo contemporáneo, especialmente las relacionadas con tecnologías y redes, sin perder su condición inicial tradicional (en este sentido, probablemente excluimos ejemplos que si bien presentan fuertemente la condición intersticial, han sido proyectados considerando aquellos elementos que ya incorporan criterios contemporáneos). Tercero, deben establecer esferas públicas y privadas, es decir, que en su concepción original los espacios hayan sido pensados bajo la construcción de ambas condiciones, posibilitando así, la aplicación de la condición intersticial.

Ahora bien, independiente a que cada espacio que se considere como caso de estudio y tenga propiedades y características particulares, en rigor, cualquier espacio donde la condición dual público-privado esté presente, tiene gran potencial de identificar al intersticio como constante.

\subsection{Caso 1: Puerta del Sol}

Situada en Madrid, España, es escenario de una espacialidad que se contrapone a una realidad contemporánea, su configuración tradicional es evidente, los edificios y su emplazamiento conforman un espacio: "una plaza", y una circulación rodada, cada una de las partes configuran un escenario que además es de carácter simbólico, es el punto neurálgico de Madrid, el km 0., y alberga edificios institucionales y comerciales. Su morfología nos presenta muestras de la intención de crear un punto de encuentro a través del cual la ciudad se articula, mantiene características nodales (Figura 2).

Esta configuración presenta una condición bastante clara en relación a lo que se constituye público y privado-institucional. La estructura espacial es rígida, sus posibilidades quedan limitadas a funciones tradicionales. De pasar a ser un espacio con intención de crear un escenario vivo de relaciones sociales, se transforma en un punto de tránsito, que funciona de conector con otros puntos de la ciudad. Recae en un espacio racionalista donde la función prima por sobre el significado social.

La flexibilidad de la sociedad actual no se identifica con la configuración tradicional, el espacio se torna ambiguo, su intención queda disminuida por la interpretación del usuario en relación a su realidad. El intersticio asoma entonces su condición dual (Fig. 3).

31 (Auge: 1993) 

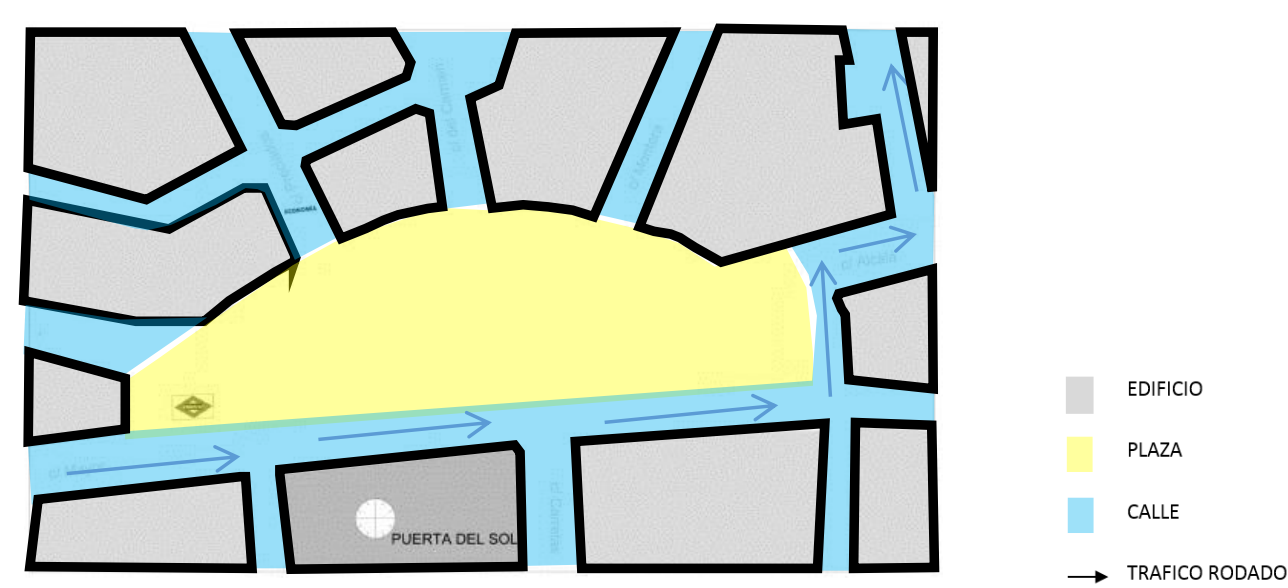

Fig. 2

Fte: Elaboración propia

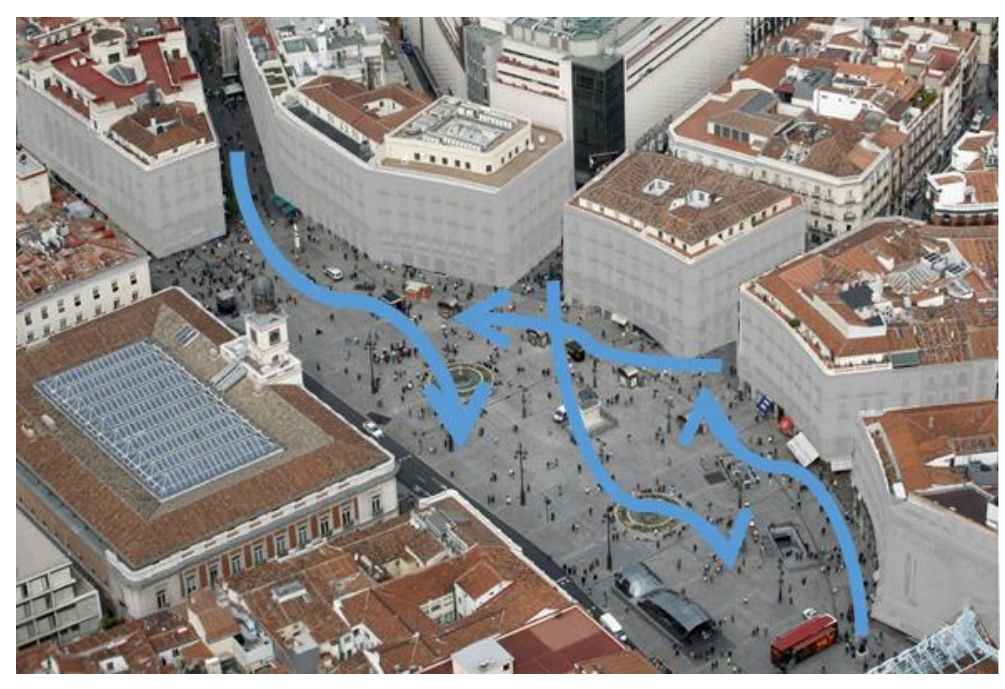

Fig. 3

Fte: http://oink.elrellano.com/desastre/madrid_desde_el_cielo.html

La calle permite el tránsito vehicular y ejerce como límite rígido de la plaza, los edificios de gran potencia morfológica y simbólica sostienen límites poco permeables, encierran actividades que disminuyen la relación con el espacio vacío (Fig. 4). Esto no es suficiente para atender y sostener una realidad contemporánea desvinculada con el escenario de estructura rígida y definida. La condición tradicional a la hora de plantear el espacio urbano y definir las partes de manera concreta obstaculiza la posibilidad de manifestación y acción social cotidiana, flexible y contemporánea que sostiene el intersticio (Fig. 5). 


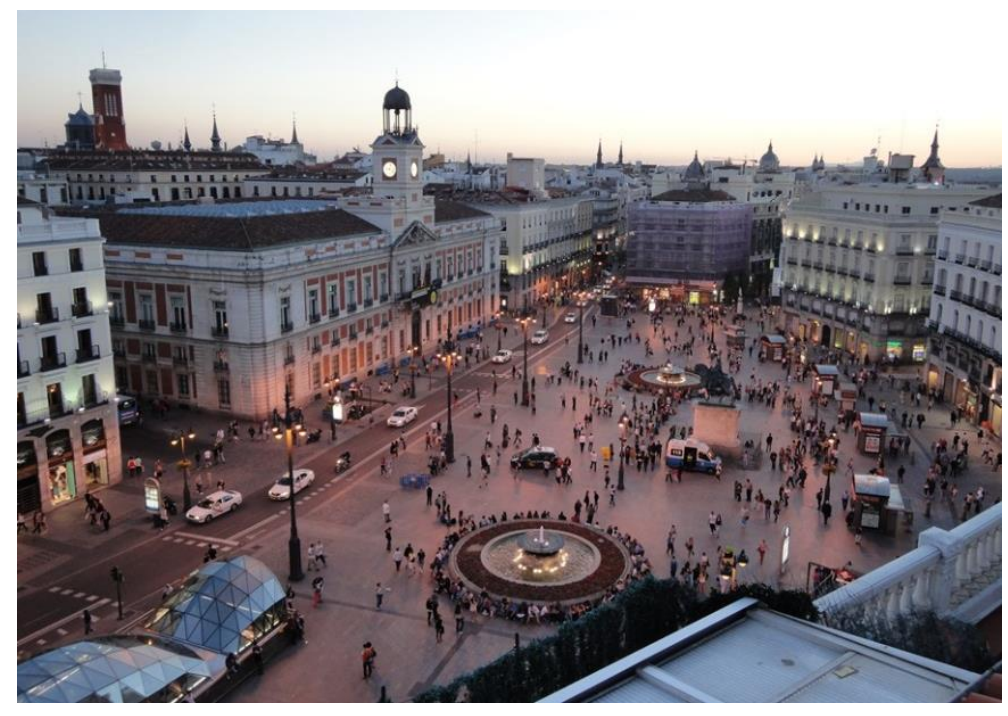

Fig. 4

Fte: http://madridman.com/blog-madrid/

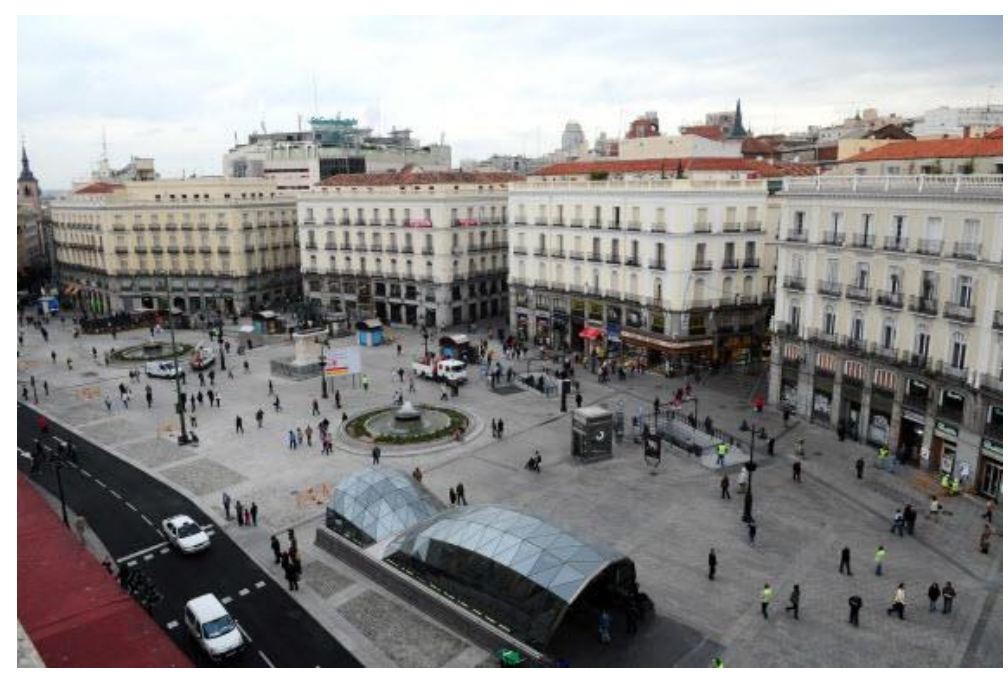

Fig. 5

Fte: http://www.respiromadrid.es/la-ciudad-para-los-ciudadanos/1782/

Durante el movimiento de los indignados en el año 2011, la Puerta del Sol sirvió de espacio de manifestación ante la disconformidad de la sociedad con sus representantes gubernamentales (Fig. 6). Este hecho sugirió la reinterpretación del espacio pensando en su potencialidad, de esta manera, el lugar volvió a adquirir un protagonismo simbólico.

Lo interesante de este fenómeno es la reinterpretación que la sociedad le otorga a este espacio público. La concurrencia masiva de este acto social, convierte al espacio en un lugar antropológico ${ }^{32}$, que gracias a las redes comunicacionales se intensifica. Las condiciones entonces

32 (Auge: 1993) 
funcionales y morfológicas del espacio se distorsionan en cuanto a la sociedad lo reinterpreta según su necesidad.

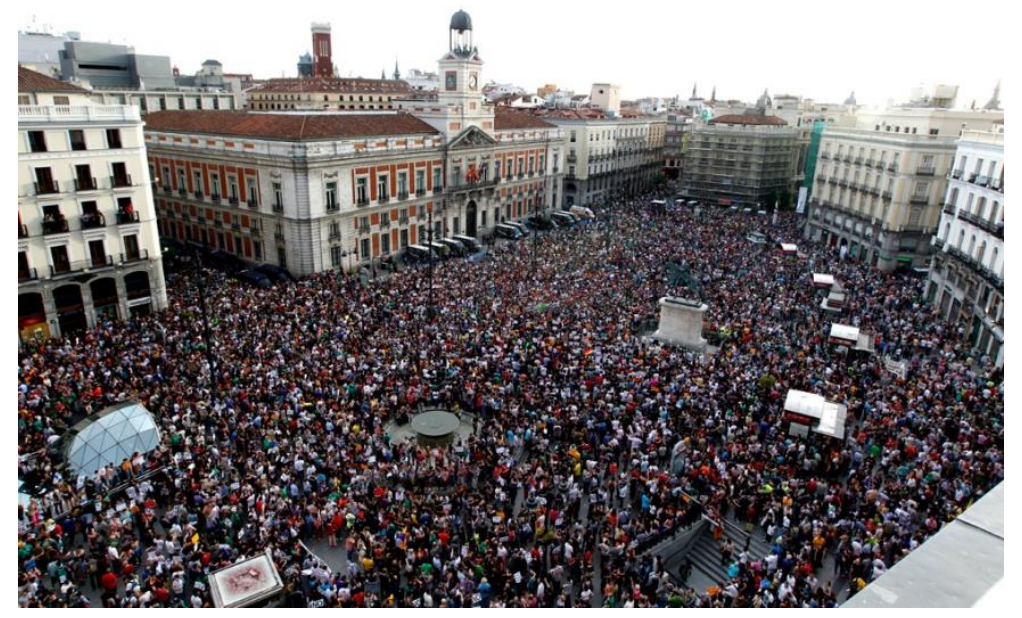

Fig. 6

Fte: http://elbuscadordelaverdad.blogspot.com/2011/

Un hecho significativo fue la acampada suscitada en este lugar, que trajo consigo una reconfiguración espacial de la plaza, con distintos programas que los mismos manifestantes proponían, que se resguardaban bajo infraestructura precaria y espontánea, pero la flexibilidad que se le da al lugar lo transforma notoriamente. Su configuración cambia, se transgreden los límites existentes, las estructuras o partes definidas tradicionalmente se transforman según la realidad del momento.
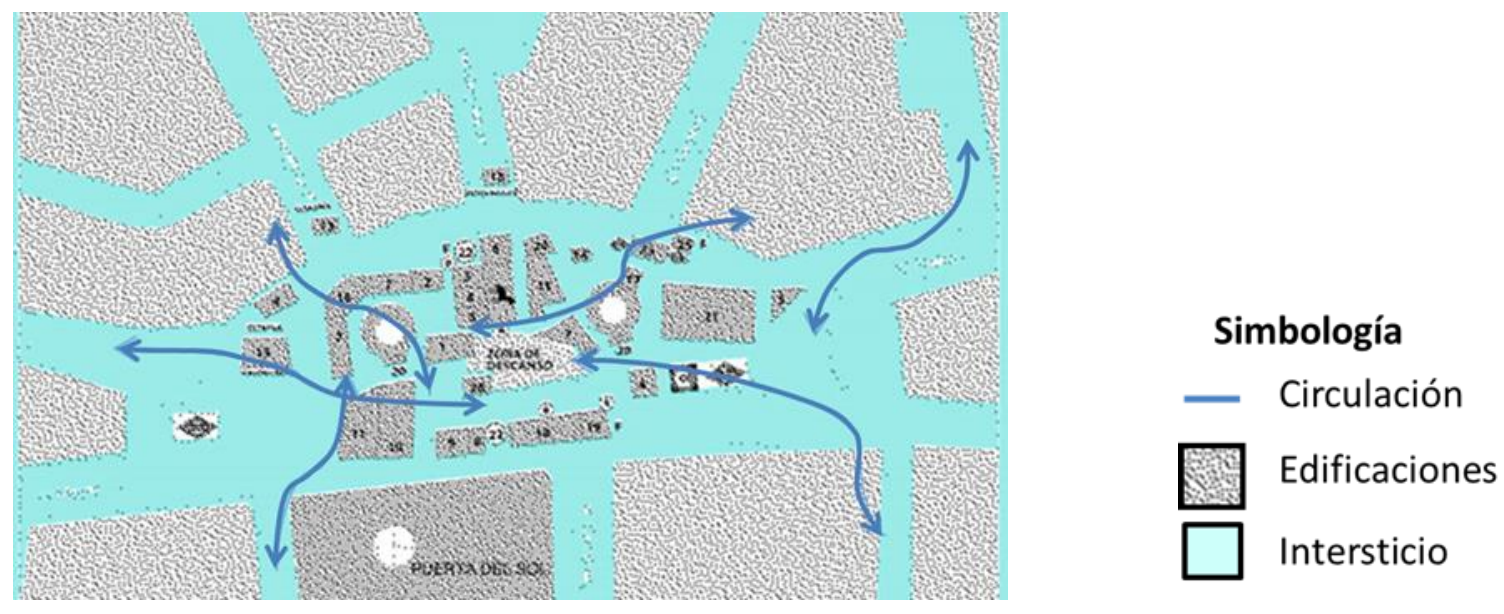

Fig. 7

Fte: Elaboración propia

De esta manera, el intersticio ahora soporta una realidad que se solventa en una configuración que se transgrede, el escenario es el mismo pero su condición cambia, se vinculan significados que la sociedad interpreta acorde a la realidad (Fig. 7). Es cierto que es un hecho aislado, pero lo que prevalece es la intención de la sociedad de modificar las leyes del espacio en torno a su configuración y función, y en este sentido, a través de la autogestión y participación se logra 
plasmar una realidad coherente a los tiempos actuales. Es acá que el intersticio cambia su condición y logra una relación homeostática entre los diferentes ámbitos que configuran la plaza (Fig. 8).

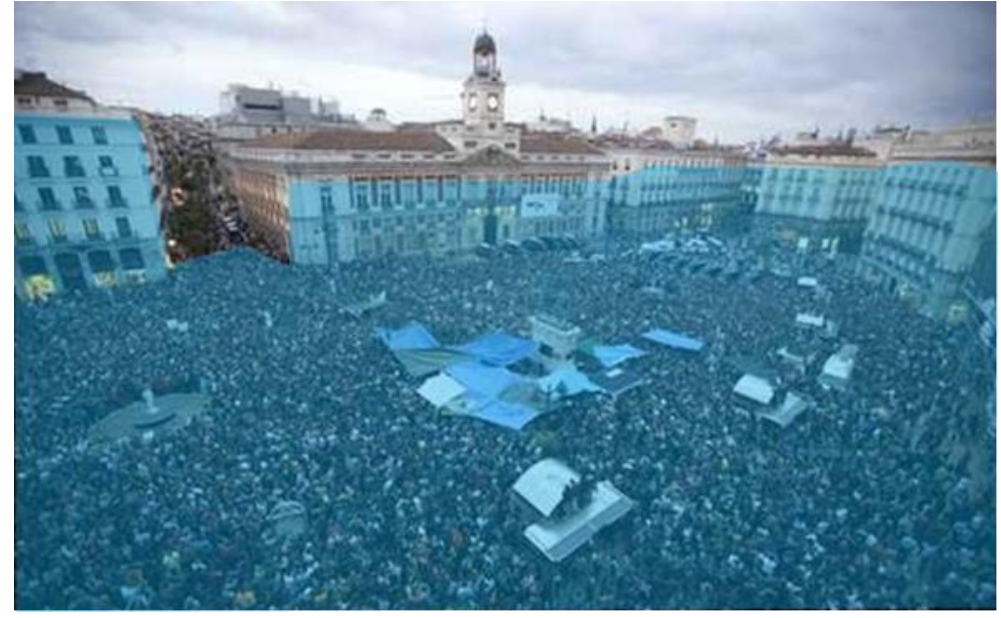

Fig. 8

Fte: http://www.elclarin.cl/

Asoma la constante del intersticio, elemento que constantemente aparece como parte del espacio público ejerciendo una relación entre las partes, (incluyendo lo inmaterial como sensaciones o emociones) la flexibilidad y dinamismo configuran el espacio de una manera distinta pero acorde a los intereses de la sociedad. El espacio intersticio se vuelve homeostático en todo sentido.

\subsection{Caso 2: Plaza de Torico}

Se emplaza en Teruel, España, evidencia la intervención de elementos perceptuales, logrando reinventar un espacio de características y tradiciones históricas, la configuración espacial de la plaza es distinta a otras, su forma triangular establecida por edificios en torno a un espacio central con limites permeables a través de portales, funcionan como espacios semipúblicos, así evidencian una condición de relación entre las partes que componen el espacio, el tratamiento de suelo utilizado es de un carácter simbólico a la vez de entregarle un dinamismo al espacio (Fig. 9).

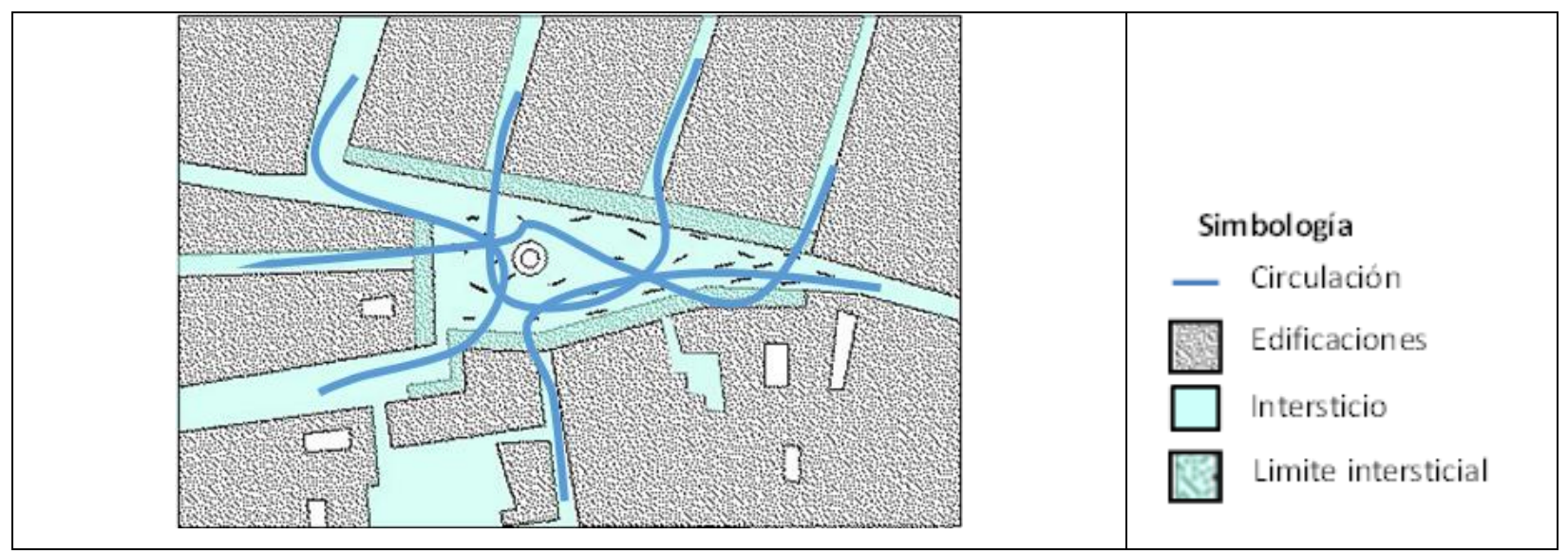

Fig. 9

Fte: Elaboración propia 
Este caso muestra una intervención más sutil, pero que ayuda a manifestar la condición natural del intersticio, aquí se evidencia físicamente características de transición en la configuración del espacio, por tanto, no existe lo público o lo privado definido como tal, sino que se establece una relación bidireccional entre ambas partes (Fig. 10).

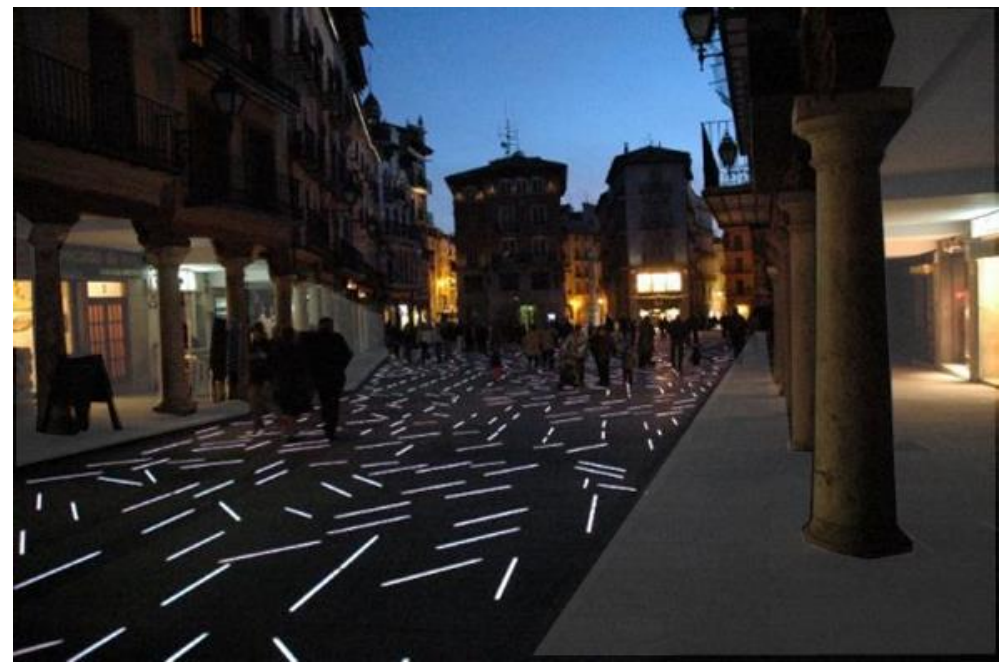

Fig. 10

Fte: http://www.20minutos.es/imagen/723832

Los espacios de transición están animados por elementos visuales (luces, colores, perspectivas, etc.) que permiten vitalizar el espacio urbano. En este entendido, perceptualmente no existe un límite definido (Fig. 11).

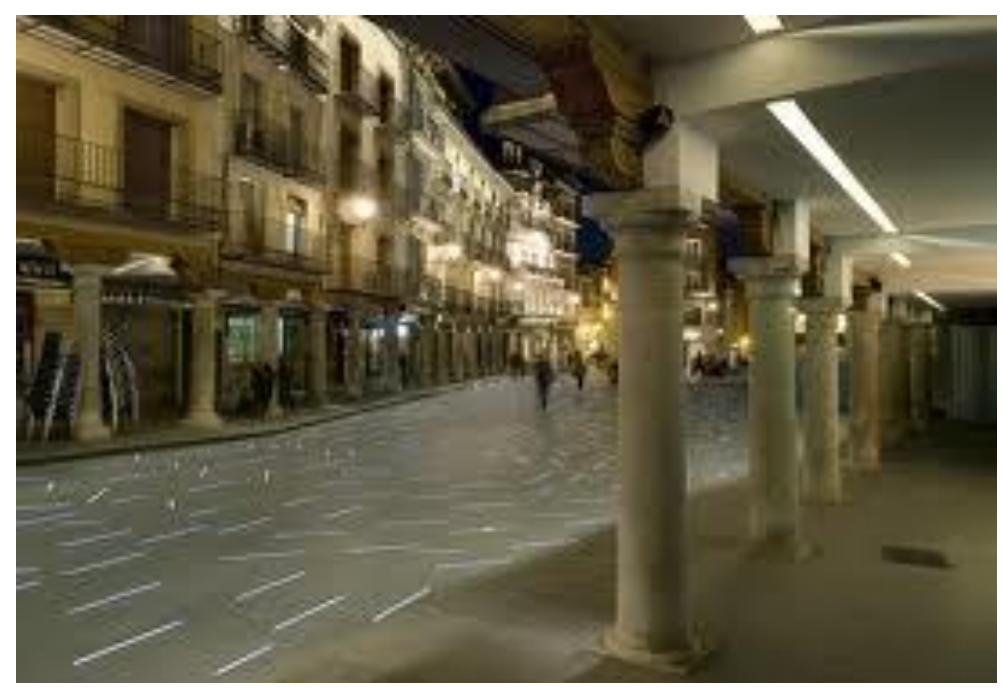

Fig. 11

Fte: http://www.mimoa.eu/projects/Spain/Teruel/Plaza\%20del\%20Torico

Ahora bien, la incorporación de elementos visuales ejerce un incentivo adicional en la manera de interpretar este espacio intersticio por parte de la sociedad, el dinamismo es evidente, y los usuarios así lo entienden, consagrándolo de distintas maneras tales como comercio, 
intervenciones culturales (fiesta de la puesta del pañuelo a la escultura del toro (Fig. 14)), circulación, que incluso influye en el otros espacios del entorno. Todo uso se entremezcla y vuelve a resaltar el intersticio como un concepto que soporta una realidad contemporánea que se sostiene, en este caso, gracias a una configuración que rompe límites establecidos de manera más tradicional (Fig. 12). El usuario percibe cada elemento espacial que configura una forma urbana resultante, que logra una relación solidaria entre tipología edificatoria y la morfología urbana ${ }^{33}$.

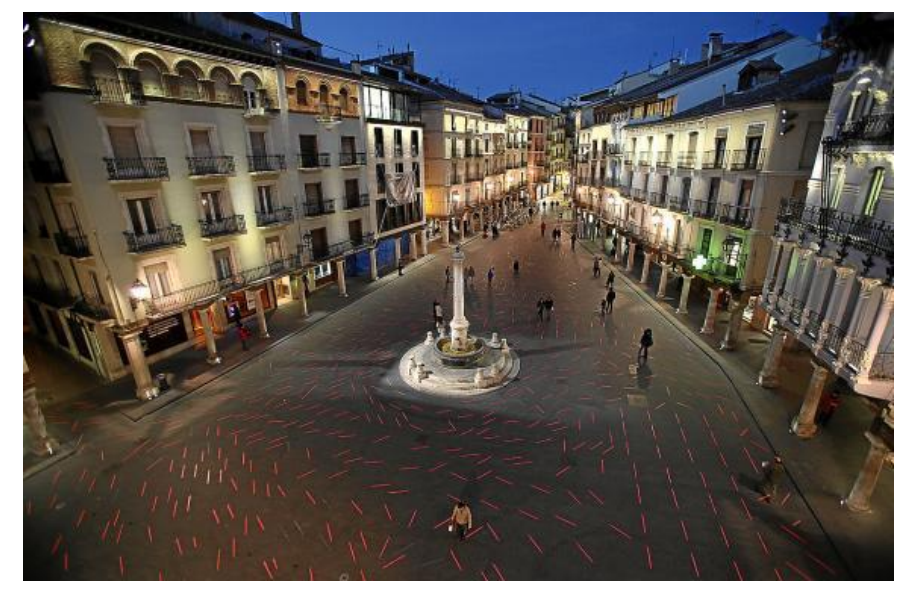

Fig. 12

Fte: http://www.heraldo.es/noticias/la_iluminacion_plaza_del_torico

En este caso, la interpretación es acorde a significados vinculados a la realidad contemporánea de la sociedad y la condición dual que se presenta. Bajo esta manera de reconfigurar el espacio, sutil pero intensa, el intersticio se convierte en la condición protagonista (Fig. 12 y Fig. 13), en un espacio que se configura físicamente de tal manera que, tanto lo público como lo privado, quedan establecidos en él, bajo sus condiciones, permitiendo una mayor flexibilidad entre uno y otro ámbito.

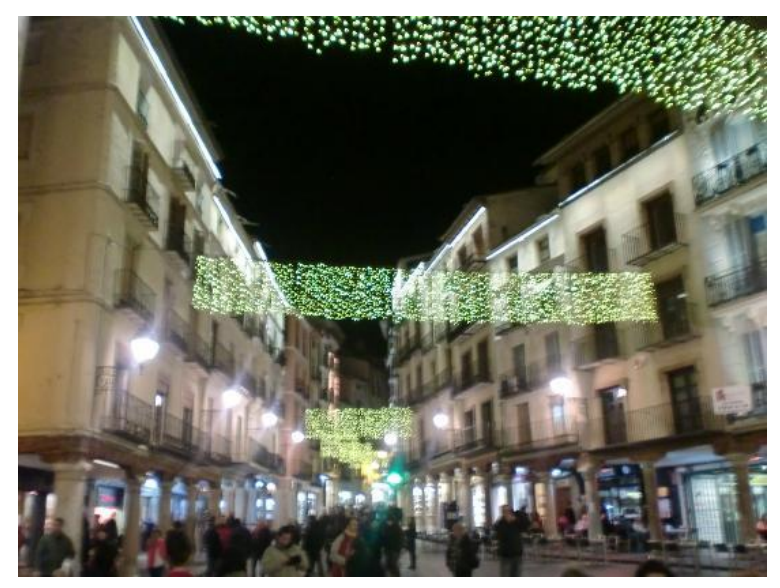

Fig. 13

Fte: http://www.tripadvisor.cl/

33 (Ordeig: 2010) 


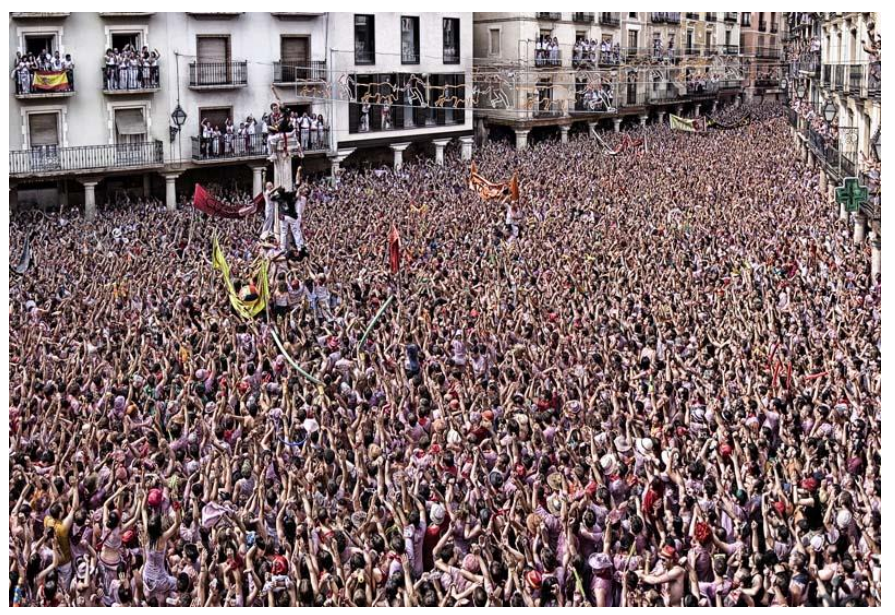

Fig. 14

Fte: http://teruelandia.blogspot.com/2013/04/

\subsection{Caso 3: La Plaza de la Encarnación}

El último caso observado es el de la Plaza de la Encarnación en Sevilla, España. Particularmente, este espacio se reinventa a través de una estructura deforme, que alberga diferentes usos y programas. A diferencia de lo existente, en otra época la plaza que se configuraba como espacio central bien configurado, rígido, donde la presencia de mesetas, ornamentaba el lugar que se transformaba en un mercado precario y transitorio, es decir, otro contexto para otra realidad (Fig. 15).

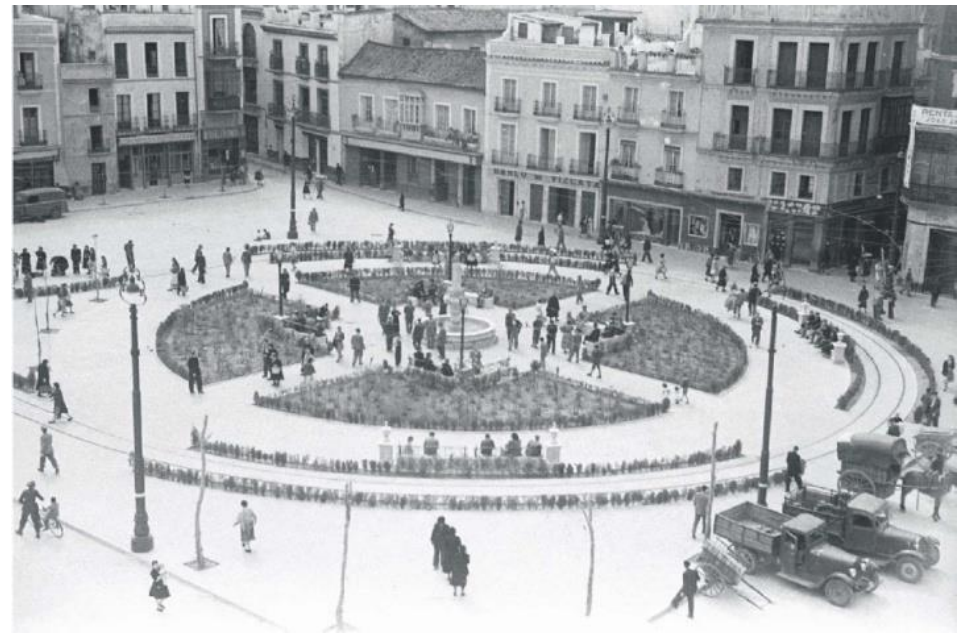

Fig. 15

http://elpaisajecotidiano.blogspot.com/

Ahora bien, en este caso el intersticio alberga una estructura que propone una configuración espacial, los edificios que ofrecen un espacio central, se transforman en benefactores de una estructura distinta e interesante por su morfología y funcionalidad, a través de ésta, la reinterpretación de la sociedad en cuanto a funciones posibles es lo que hace que el intersticio se desenvuelva en su condición natural. La intención de la estructura ofrece permeabilidad, más allá de sus límites fijos, su protagonismo influye en relación a la percepción de los usuarios que 
vinculan a la estructura con posibles significados de la realidad más contemporánea, el espacio se interpreta de acuerdo a lo que se necesite, se torna flexible y se amolda, se permite el paseo, el tránsito, manifestaciones culturales, el comercio, la relación social en todo sentido, es un espacio adaptable (Fig. 16).

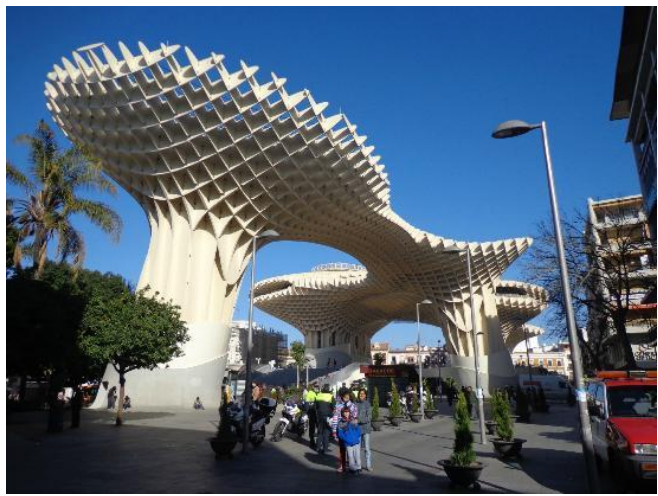

Fte: http://elabismodeantonio.blogspot.com

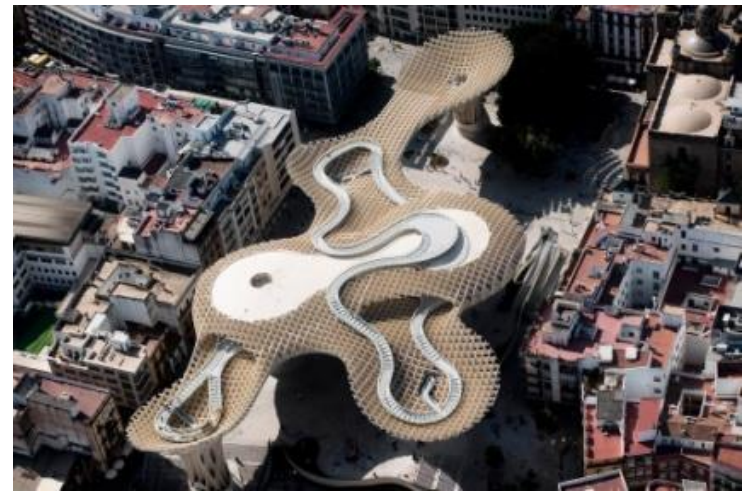

Fig. 16

El objeto rompe el sentido tradicional del escenario, la forma adquiere un carácter primordial, por ende le entrega una nueva condición simbólica al lugar (Fig. 17, Fig. 18 y Fig. 19).

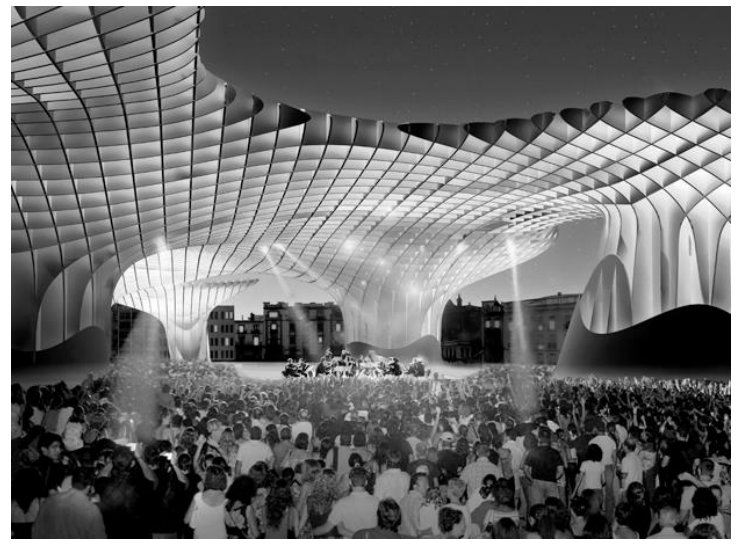

Fig. 17

Fuente: http://noticias.arq.com.mx/Detalles/

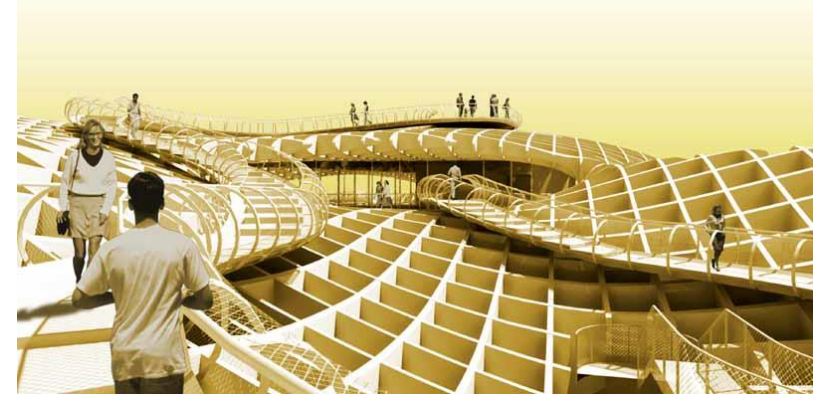

Fig. 18

Fuente: http://www.sevilla21.com/ 


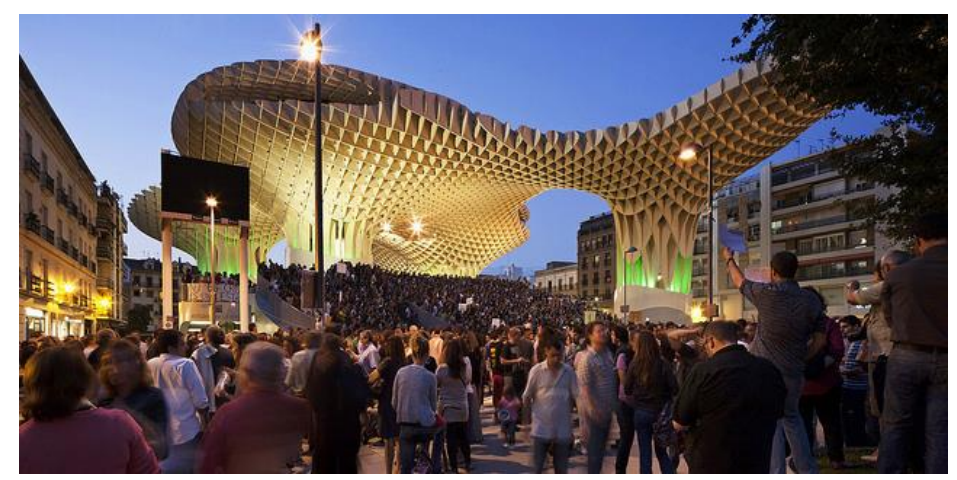

Fig. 19

Fuente: http://www.hoyesarte.com/s15-blogs/c115-arte-y-arquitectura/

La configuración tradicional que conforma el espacio en este caso, tanto la calle, plaza o edificio, se vinculan entre sí de tal manera de adaptarse a la realidad que genera esta estructura en el entorno, el intersticio por ende, rompe con su condición dual, entonces, la disfuncionalidad entre lo físico espacial y lo interpretativo social no se evidencia al plasmar un espacio que permite su reinvención y adaptación de la realidad contemporánea con una estructura de forma irregular, que busca principalmente, generar significados distintos, más que funciones determinadas atrapadas en una forma concreta, consagrando una crítica en relación a la configuración espacial racional.
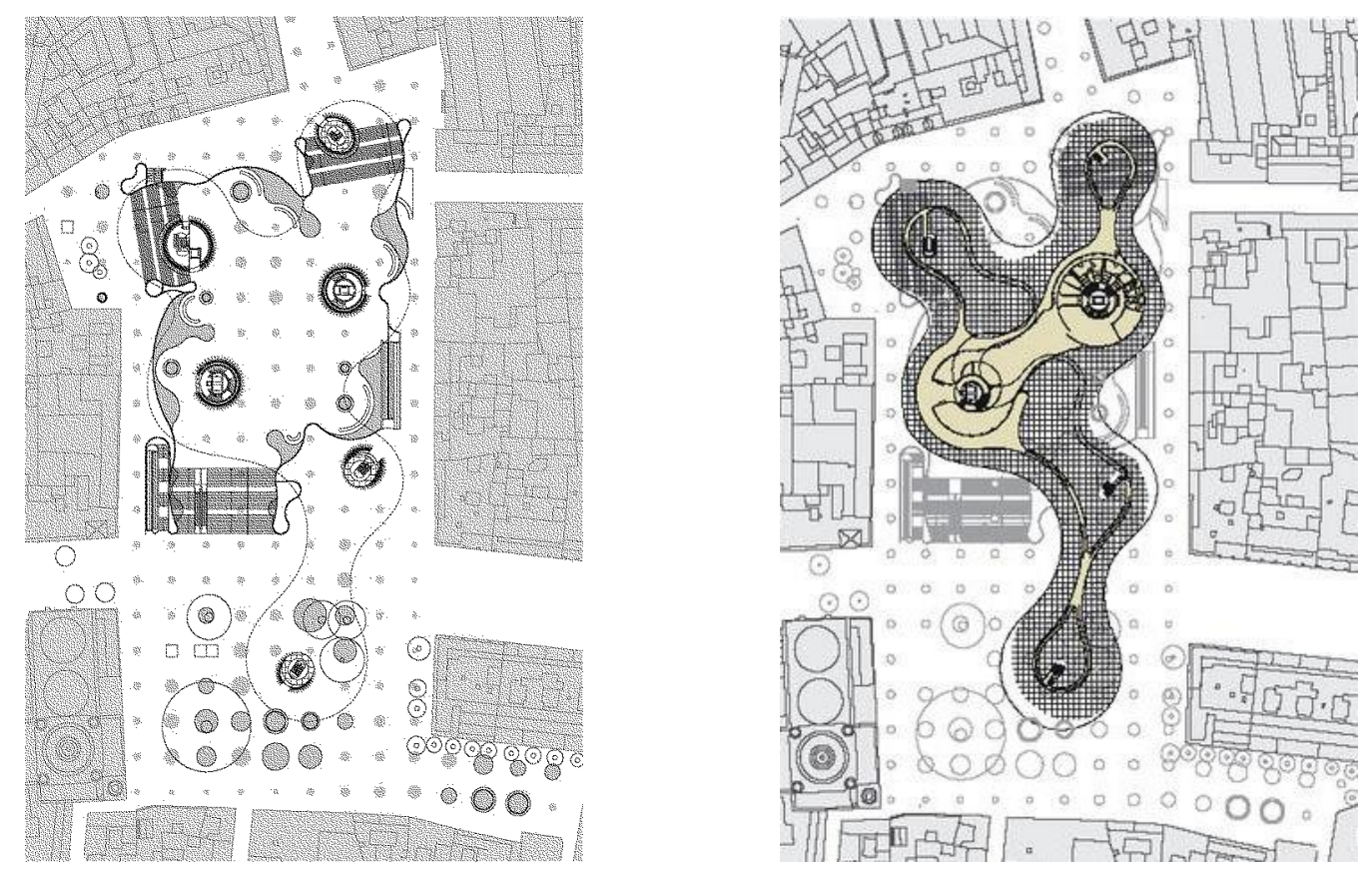

Fig. 20 Izquierda: Planta primer Nivel. Derecha: Planta de cubierta Fte: http://www.hoyesarte.com/s15-blogs/c115-arte-y-arquitectura/ 


\section{REVISTA DE \\ URBANISMO}

ISSN 0717-5051

http://revistaurbanismo.uchile.cl
Revista de Urbanismo No31 - Julio - Diciembre de 2014 Departamento de Urbanismo - FAU - Universidad de Chile

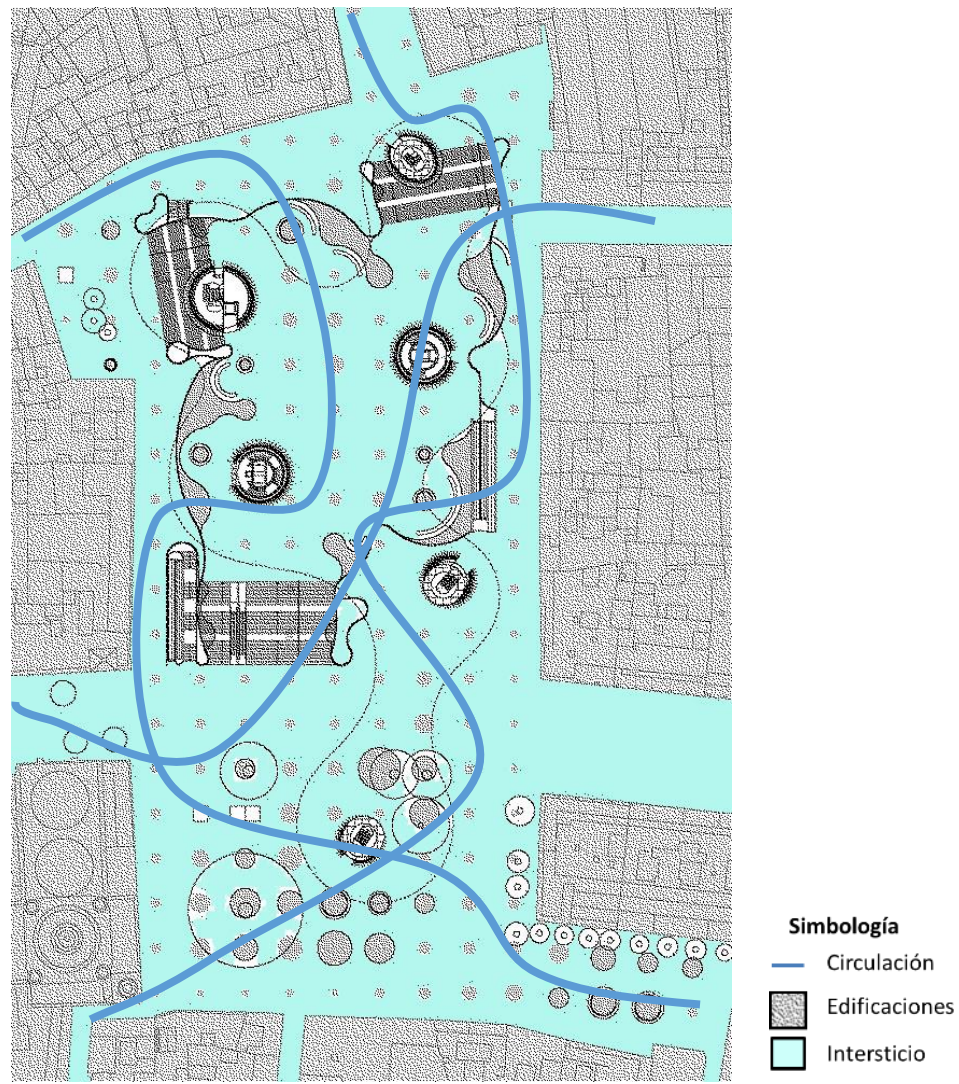

Fig. 21

Fte: http://www.hoyesarte.com/s15-blogs/c115-arte-y-arquitectura/

Así, emerge la constante de intersticio (condiciones dinámicas y flexibles que se van articulando) a través del despliegue de la sociedad contemporánea (Fig. 21)

\section{Categorías de Análisis (Modos de Intervención)}

El diseño urbano contemporáneo puede ser capaz de superar las limitaciones de las corrientes tradicionales, debido a que el modo de configurar el espacio urbano de la ciudad se traduce a delimitar o definir lo que es público o privado, abierto o cerrado, rígido o permeable. Bajo este hecho, y sobre la reinterpretación del concepto de intersticio, es posible abordar la condición dual público-privado, la cual es necesaria superar para que el intersticio cumpla con su constante, entendiendo este concepto como el medio transitorio, en el cual se despliega la sociedad contemporánea.

Por tanto, el nuevo desafío del diseño urbano actual se centra en permitir condiciones espaciales, configuraciones 0 intervenciones que generen esta constante intersticial sugiriendo interpretaciones contemporáneas de la realidad social.

En los tres casos expuestos, encontramos variables o condiciones que por una parte, configuran el espacio de una manera tradicional y por otra parte, paralelamente, evidencian una dualidad entre las partes que lo conforman (público-privado, abierto-cerrado, etc.). El intersticio bajo estas condiciones no cumple con su constante por lo tanto, el usuario reinterpreta según sus necesidades e intereses el espacio urbano tradicional. 


\section{URBANISMO}

ISSN 0717-5051

http://revistaurbanismo.uchile.cl
Revista de Urbanismo N³1 - Julio - Diciembre de 2014 Departamento de Urbanismo - FAU - Universidad de Chile
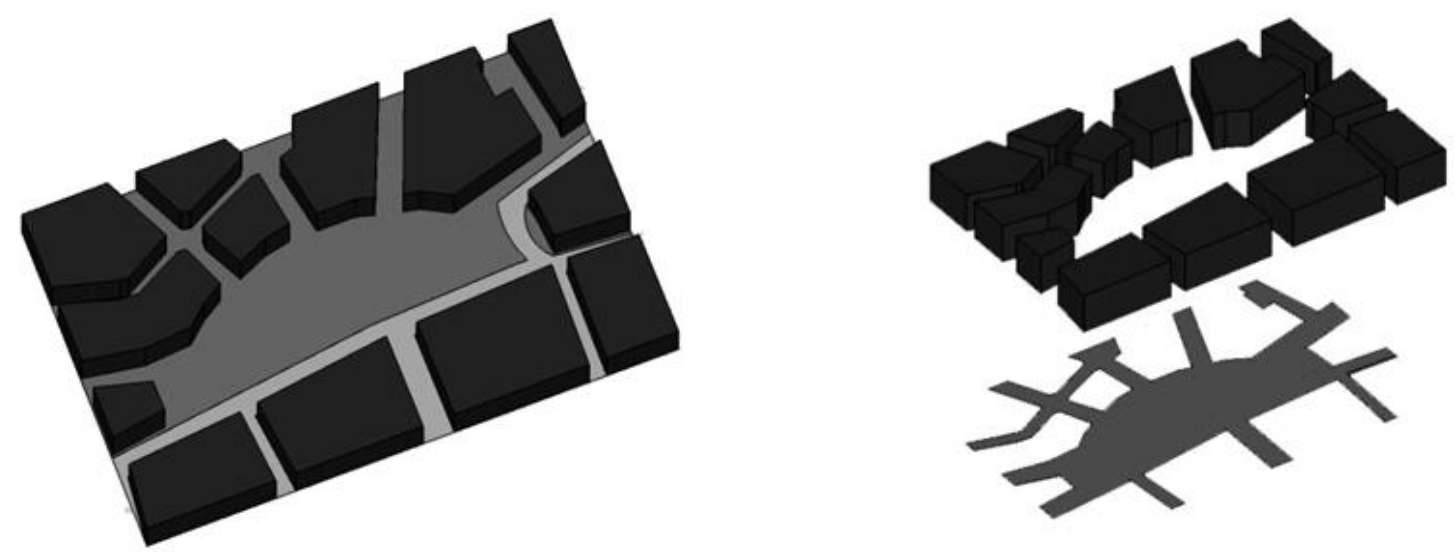

Fig. 22 Caso 1. Puerta del Sol. Izq: Configuración espacial tradicional. Der: Dualidad público-privada Fte: Elaboración propia
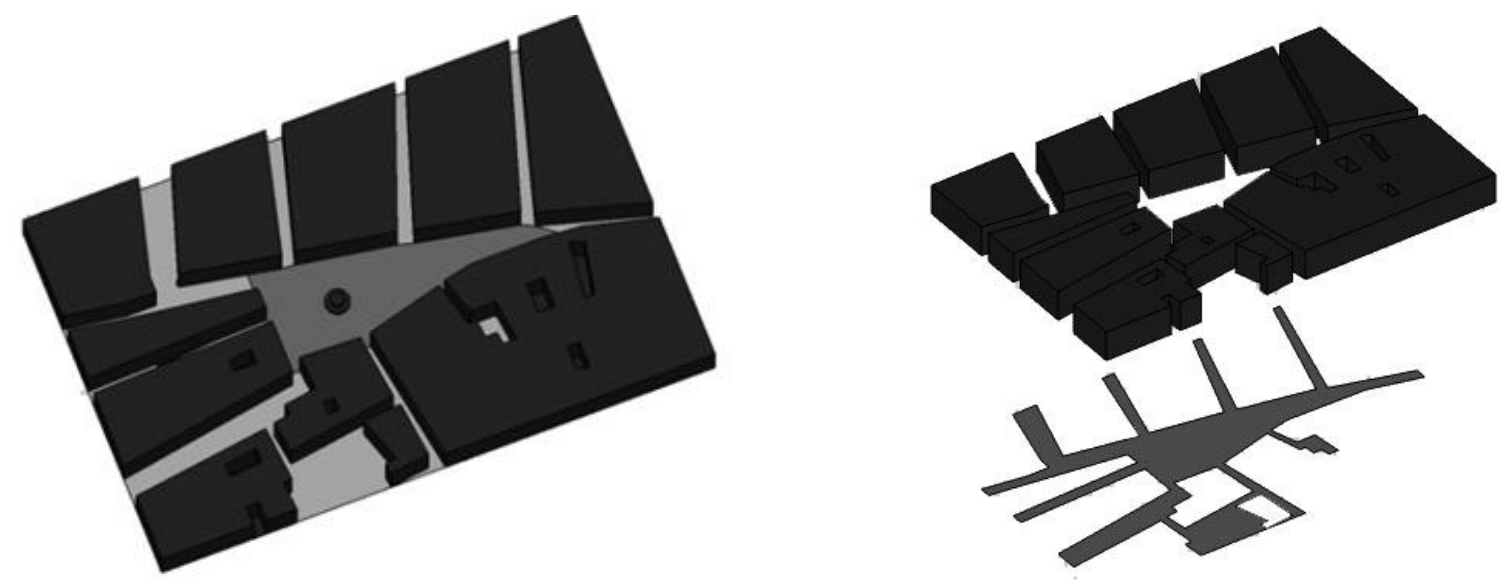

Fig. 23 Caso 2. Plaza de Torico. Izq: Configuración espacial tradicional. Der: Dualidad público-privada Fte: Elaboración propia
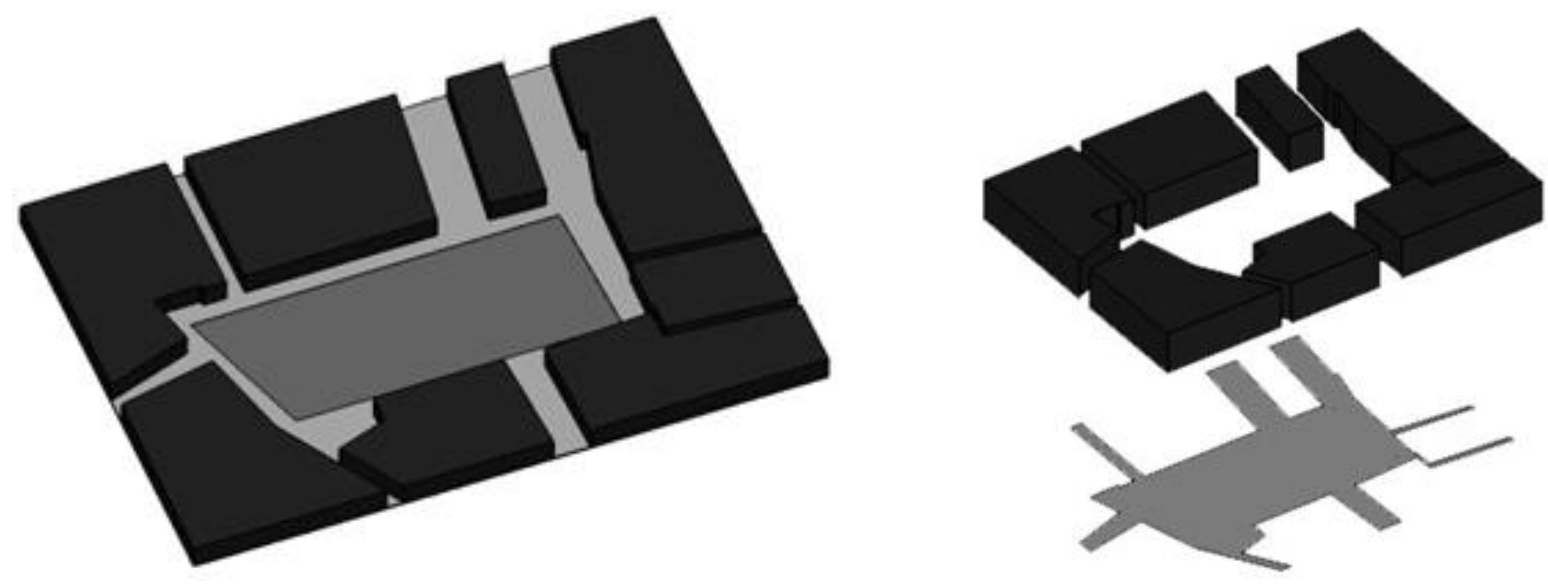

Fig. 24 Caso 3. Plaza de la Encarnación. Izq: Configuración espacial tradicional. Der: Dualidad públicoprivada

Fte: Elaboración propia 


\section{REVISTA DE \\ URBANISMO}

ISSN 0717-5051

http://revistaurbanismo.uchile.cl
Revista de Urbanismo N031 - Julio - Diciembre de 2014 Departamento de Urbanismo - FAU - Universidad de Chile

Asimismo, en todos los casos observados la reinvención del espacio urbano, logra emerger ante la constante del intersticio, que permite la relación entre las partes, y al mismo tiempo, un dialogo bidireccional, que da cuenta de un espacio que soporta la manera contemporánea en la que se desenvuelve la sociedad actual. Aquellos limites tangibles que separan formas y roles específicos, desaparecen intangiblemente, entendiendo que éstos forman parte de un solo soporte denominado "intersticio". Sobre la base de las reflexiones previamente tratadas, se esbozan tres categorías que aproximan la condición de intersticio al Diseño Urbano:

\section{A) Autogestión participativa.}

Bajo esta categoría de reinvención, los parámetros tradicionales y funcionales que configuran un espacio, se vuelven retrógrados, y no permiten asumir el carácter simbólico que denota el lugar, es la sociedad que permite elaborar este simbolismo, y a través de instalaciones espontaneas resuelve una configuración espacial acorde a su realidad. Se le otorga un significado contemporáneo al espacio urbano, que se sustenta en el intersticio.
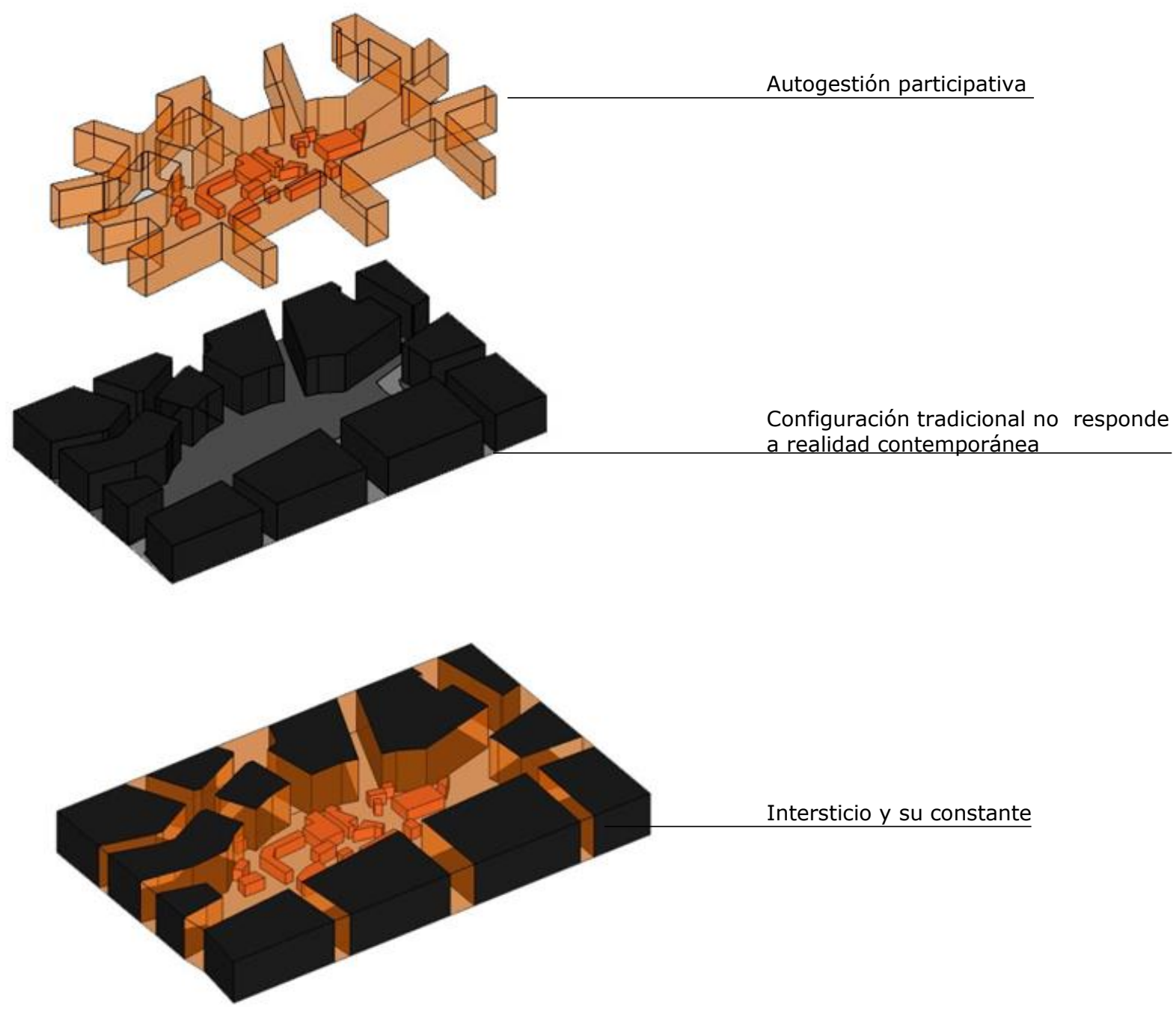

Fig. 25 Caso 1: Puerta del Sol

Fte: Elaboración propia 


\section{REVISTA DE \\ URBANISMO}

ISSN 0717-5051

http://revistaurbanismo.uchile.cl
Revista de Urbanismo N³1 - Julio - Diciembre de 2014 Departamento de Urbanismo - FAU - Universidad de Chile

\section{B) Elementos perceptuales.}

Se establecen nuevos escenarios que permiten relacionar al espacio con el usuario de manera sensorial, el racionalismo se desliga de la nueva propuesta, que además hace referencia conceptual al dinamismo en la cual se despliega la sociedad. Los espacios de transición, presentes en la plaza de Torico son elementos que se perciben como indefinidos, por tanto, logra una configuración espacial que vincula lo abierto y lo cerrado, además de aprovechar su condición espacial para contener múltiples funciones de intereses sociales. La nueva configuración que presenta, rompe con esquemas tradicionales, los que son también interpretados por el usuario, el soporte del intersticio asoma como constante.

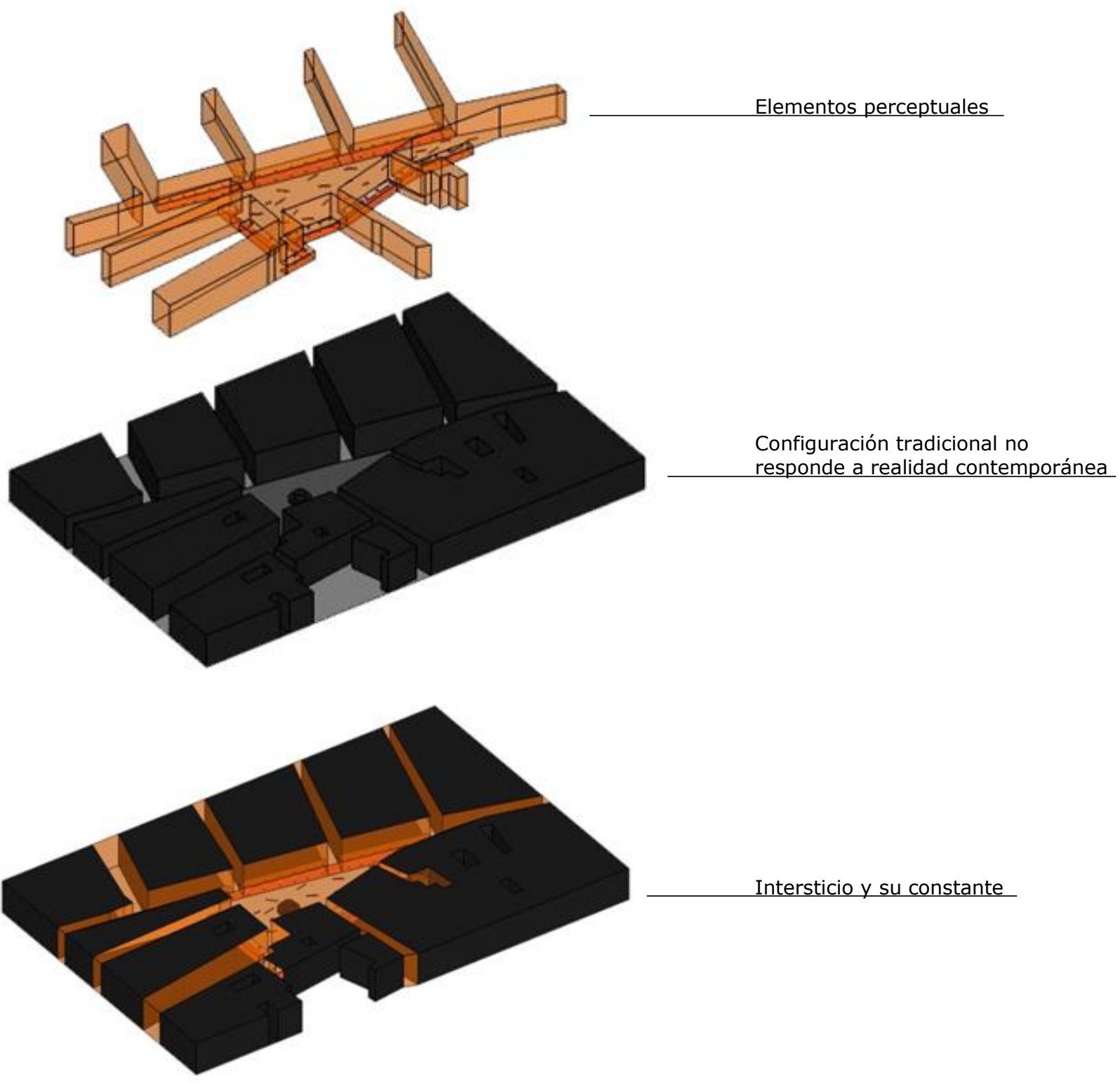

Fig. 26 Caso 2: Plaza de Torico

Fte: Elaboración propia 


\section{REVISTA DE \\ URBANISMO}

ISSN 0717-5051

http://revistaurbanismo.uchile.cl
Revista de Urbanismo N³1 - Julio - Diciembre de 2014 Departamento de Urbanismo - FAU - Universidad de Chile

\section{C) Lineamiento simbologista.}

Propuesta radical que en todo sentido rompe con lo tradicional racional, la descomposición de formas establecidas, trae consigo funciones y significados distintos pero acordes a los intereses de la sociedad contemporánea, permite la flexibilidad, adaptabilidad y multifuncionalidad, el objeto permite también cohesionar las partes que configuran el espacio desapareciendo límites y roles típicos.
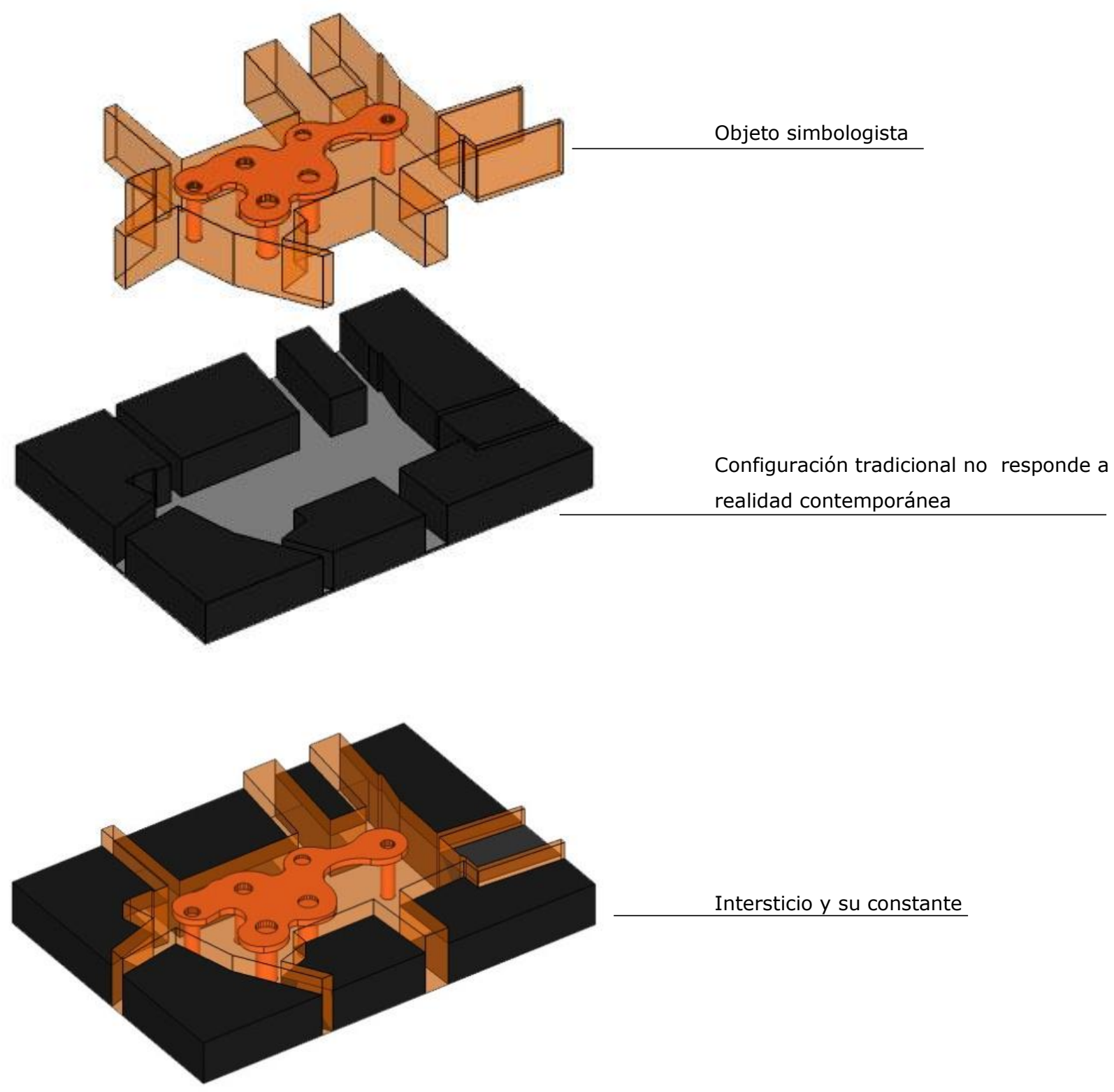

Intersticio y su constante

Fig. 27 Caso 3: Plaza de la Encarnación

Fte: Elaboración propia 


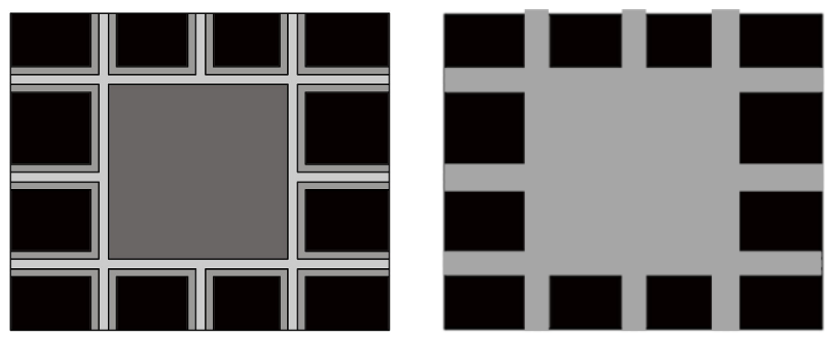

Fig. 28 Izq: Espacio urbano tradicional. Der: Reconceptualización intersticio Fte: Elaboración propia

El espacio urbano tradicional evidencia claramente los límites y funciones en la calle y la plaza, propios de aquellas aproximaciones e intervenciones tradicionales que despliegan estrictamente sus límites. Así, la reconfiguración del intersticio propone superar aquellos límites establecidos por las condiciones formales y funcionales, haciendo desaparecer los límites entre la calle y la plaza, entendiendo un nuevo soporte de uso público.

\section{Reconfiguración del Espacio Urbano}

La reinvención del espacio urbano en relación a la constante del intersticio como soporte en el cual se desenvuelve la sociedad, al parecer radica en la necesidad de vincular significados acordes a la realidad actual, entendiendo que los roles específicos que configuran el espacio tradicional urbano se vuelve disfuncionales al usuario contemporáneo. De aquí entonces se desprende una nueva manera de entender el espacio urbano, que en todo momento debe consignar un significado más que una establecida función.
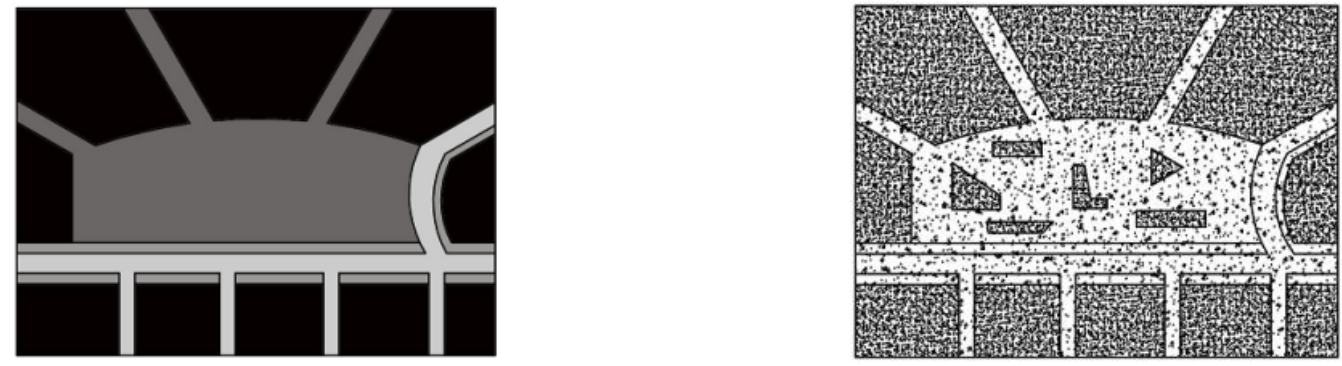

Fig. 29 Caso 1: Puerta del Sol

Fte: Elaboración propia
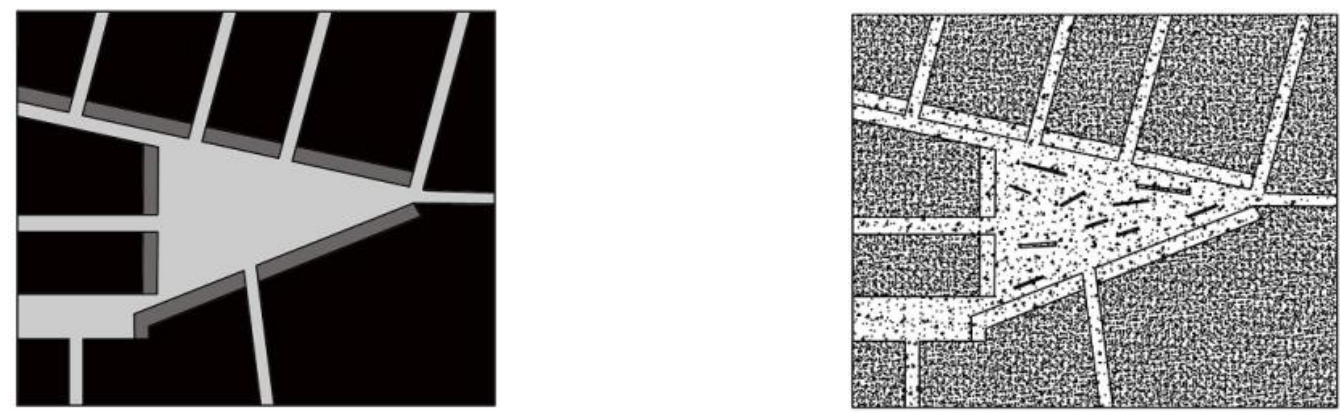

Fig. 30 Caso 2: Plaza de Torico

Fte: Elaboración propia 

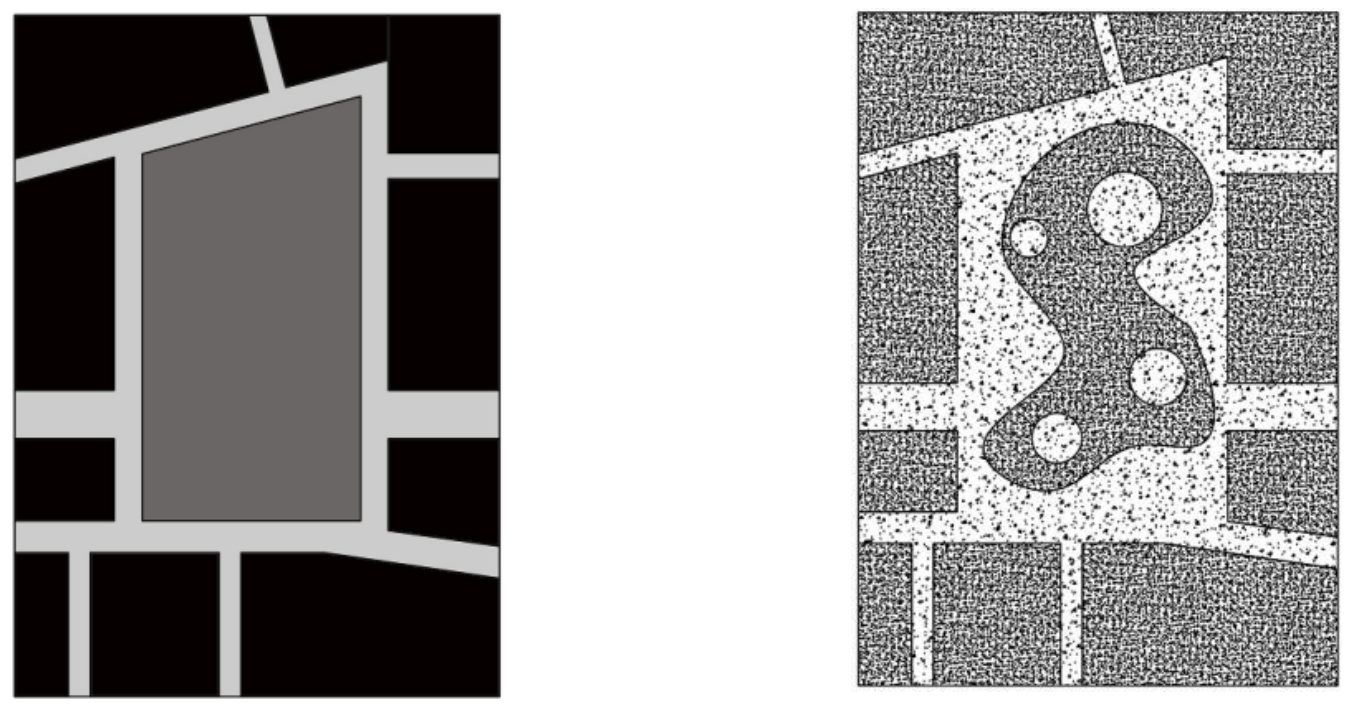

Fig. 31 Caso 3: Plaza de la Encarnación

Fte: Elaboración propia

En los tres casos observados, si bien evidencian su configuración tradicional por origen, es posible generar una lectura de las posibilidades que estos espacios ofrecen en la contemporaneidad. En esta condición intersticial, la dualidad público - privada se permeabiliza hasta posiblemente desaparecer, por lo menos desde el punto de vista perceptual. Los significados de la realidad contemporánea a través de la flexibilidad de sus espacios, producto de actividades y programas, la dinámica que ofrece para el usuario junto con las funciones múltiples temporales 0 atemporales, fortalecen la identidad del lugar.

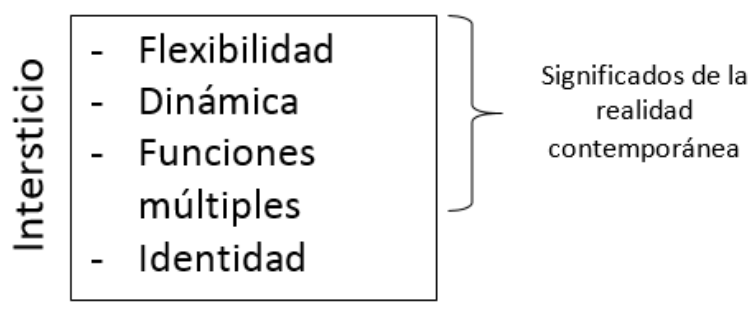

Fig. 32

Fte: Elaboración propia

Umberto Eco propone que todo significado denota una función posible de realizar por el usuario ${ }^{34}$, entonces bajo la intención de reconfigurar el intersticio, el significado debe entenderse como flexible y dinámico, denotando más de una posible función, y que permita en su acto la relación de las partes que configuran el espacio urbano.

\section{Conclusiones y consideraciones finales.}

La exploración del concepto de intersticio como se ha descrito, nos ayuda a reflexionar acerca de cómo podría utilizarse la herramienta del diseño urbano en términos contemporáneos, y superar las limitaciones que existen hoy en día en cuanto a propuestas de diseño que constituyen las urbes.

${ }^{34}$ (Eco: 1974) 
Así, se ha demostrado como la condición dual presente en el intersticio debido a la confrontación de lo público y lo privado, y a sus roles o papeles específicos, se torna disfuncional en relación al despliegue dinámico y flexible en el que se desenvuelve la sociedad actual.

Las condiciones solamente orientadas a la resolución física formal y funcional son insuficientes para poder entender la contemporaneidad de la sociedad. Por ello, se presenta como criterios imperantes, la autogestión participativa, clave a la hora de orientar nuevas formas de ocupar y entender el espacio, considerando el despliegue perceptual del usuario permitiendo un entorno más flexible, adaptable y multifuncional.

En todos los casos observados lo importante fue evidenciar que existen maneras de reconfigurar el espacio urbano y superar la dualidad público - privado que existe entre las partes que configuran el espacio de forma tradicional. La relación desde la perspectiva socio espacial demuestra que dicha dualidad conlleva una reinterpretación del espacio, ya que no responden a una realidad contemporánea. De esta manera, la reconceptualización del intersticio propone el soporte en el cual el diseño urbano contemporáneo debe enfocarse para resolver esta problemática, cambiando la manera tradicional de concebir el espacio urbano.

La reconceptualización del intersticio en el despliegue del diseño urbano, permite entender la realidad contemporánea de las sociedades, y además atender a sus nuevas necesidades e intereses. Entonces, la importancia de generar significados que sean coherentes a la realidad, es de vital importancia a la hora de reconfigurar el espacio urbano para que asome la constante del intersticio, como queda demostrado en los casos de estudio. Sin embargo, esta nueva reconceptualizacion del intersticio es solo un paso inicial, lo cual implica seguir profundizando en relación al concepto mismo y de qué manera puede ayudar a entender la realidad contemporánea, de manera de servir a la disciplina del diseño urbano.

Lo importante aquí es entender que el intersticio es en todo sentido, un soporte que se sostiene en un espacio físico único, en el cual se presentan relaciones físico sociales, así, su reconfiguración busca la manera de superar esta dualidad inclusive penetrando o transgrediendo límites edificatorios concebidos de manera tradicional.

Por último, recalcar que la condición intersticial se presenta en todo ámbito, no solo en el urbanismo, también se aprecia en la arquitectura, por tanto, se pueden explorar muchos casos que den cuenta de la condición del intersticio en grandes ciudades de chile, permitiendo tal vez futuros análisis e investigaciones, y de esta manera, reforzar el concepto desde una perspectiva más concreta y próxima.

\section{Bibliografía.}

ACUÑA, P. (2005). Análisis formal del espacio urbano aspectos teóricos. Instituto de investigación de la facultad de Arquitectura Urbanismo y Arte. Lima

ARZE, G., CALDERON, E. y MUÑOZ, C. (2013). El Intersticio en la dinámica de la ciudad contemporánea, Teoría y práctica del Diseño Urbano para la reflexión de la ciudad contemporánea, Santiago-Concepción, Chile.

AUGE, M. (1993). Los no lugares, espacios del anonimato. Barcelona. Editorial Gedisa.

BACON, E. (1974). Design of Cities. Viking Press: New York, 1974.

BAUMAN, Z. (2003). Modernidad Líquida. Fondo de Cultura Económica, Buenos Aires, Argentina.

BAUMAN, Z. (2006). Comunidad. En busca de seguridad en un mundo hostil. Editorial Siglo XXI, España. 
BENCOMO, C. (2011) Articulo trienal de investigación. Las teorías del diseño urbano en la conceptualización de espacio urbano y sus dos categorías: espacio público y espacio privado. Universidad Central de Venezuela Facultad de Arquitectura y Urbanismo

CARMONA, M. (2003) Public Places, Urban Spaces. The Dimensions of Urban Design. Architectural Press, Oxford, United Kingdom.

CASTELLS, M. (2002). La era de la información La sociedad red. Editorial Alianza

CULLEN, G. (1974). "Townscape". London, The Architectural Press. 1091. (El Paisaje Urbano. Tratado de estética urbanística. Barcelona, Editorial Blume.

DELGADO, M. (1999). El Animal Público. Hacia una antropología de los espacios urbanos. Editorial Anagrama, España.

ECO, U. (1974). La estructura ausente. Arquitectura y comunicación. Editorial Lumen.

GEHL, J. (2003). La Humanización Del Espacio Urbano, La Vida Social Entre Los Edificios. Traducido de la 5 a Edición Inglesa. Life Between Buildings: Using Public Space. Danish Architectural Press, Copenhague, 2003. Editorial Reverte, SA. Barcelona, 2006.

HARVEY, D. (1989). La condición de la postmodernidad. Posmodernismo en la ciudad: arquitectura y diseño urbano. Amorrortu Editores.

JOSEPH, I. (2002). El Transeunte y el Espacio Urbano. Sobre la Dispersión y el espacio urbano. Gedisa Editores, Barcelona, España.

LEFEBVRE, H. (1974) La producción del espacio.

LYNCH, K. (1960). La imagen de la ciudad. Editorial Gustavo Gili.

MANCUSO, F. (1980). Las experiencias del zonning. Editorial Gustavo Gili.

ORDEIG, J. M. (2004). Diseño Urbano y pensamiento contemporáneo. Editorial Monsa, Barcelona.

ORDEIG, J. M. (2010). Estructuralismos Urbanos. Articulo Escuela técnica superior de arquitectura Universidad de navarra, Pamplona.

SENNETT, R. (1978). El declive del hombre público. Editorial Anagrama, España.

TRIEB, M. (1983). Diseño Urbano, Teoría y Práctica. Seminario dictado por el Prof. Trieb. Facultad de Arquitectura y Urbanismo, Universidad de Chile, Santiago, Chile.

VALENCIA, M. (2005). Estudios sobre lo urbano. Deslindes disciplinarios y campos temáticos emergentes. Proyecto de Investigación. CEAUP. 